\title{
Nuevas evidencias que soportan la escisión de la formación Silgará y propuesta de un nuevo marco estratigráfico para el basamento metamórfico del Macizo de Santander (Cordillera Oriental de Colombia)
}

\author{
Luis Carlos Mantilla-Figueroa ${ }^{1}$, Carlos Alberto García-Ramírez ${ }^{1, *}$, Víctor A. Valenciaª \\ ${ }^{1}$ Escuela de Geología, Universidad Industrial de Santander, Bucaramanga, Santander, Colombia \\ ${ }^{2}$ School of Environment, Washington State University, Pullman, WA, USA
}

\begin{abstract}
Resumen
Estudios geocronológicos recientes realizados en la Formación Silgará (nombre original asignado a un grupo de esquistos y filitas aflorantes al SW del Macizo de Santander), han servido de base para proponer la escisión de ésta formación en las siguientes unidades: Esquistos del Silgará s.s., Esquistos del Chicamocha y, Filitas de San Pedro. Estas unidades, se caracterizan por presentar diferentes litologías metamorficas y diferentes edades de depositación de su protolito.

En el contexto de ideas antes referido, el trabajo que aquí se presenta tiene como propósito aportar nuevas evidencias que apoyan la propuesta de escisión antes referida, a partir de análisis isotópicos del Hf en zircones detríticos presentes en cada una de las tres unidades ya referidas, y puntualmente a partir de análisis de geoquímica de roca total. Adicionalmente, con base en la información geológica acumulada, se plantea un nuevo marco estratigráfico para el basamento metamórfico del Macizo de Santander. (c) Acad. Colomb. Cienc. Ex. Fis. Nat. 2016.
\end{abstract}

Palabras clave: Colombia, Macizo de Santander, Formación Silgará, zircones detríticos, geoquímica isotópica del Hf.

New evidence supporting the Silgara formation' split-off and proposal of a new stratigraphic framework for the metamorphic basement of the Santander Massif (Colombian Eastern Cordillera)

\begin{abstract}
The latest geochronological studies carried out in the Silgara Formation (an original name given to a group of schist and phyllites outcropping southwestern Santander Massif), has provided the basis for proposing this formation's split-off in the following units: Silgara Schist s.s., Chicamocha Schist and San Pedro Phyllites. These units are characterized by its different metamorphic lithologies and by its different protolith deposition' ages.

In the context of the aforementioned ideas, the current work aims to provide new evidences supporting the referred proposal concerning the Silgara Formation' split-off, based on detrital zircons isotopic analysis from the already mentioned new three metamorphic units and on some whole rock geochemistry analysis as well. Likewise, based on the accumulated geological information, a new stratigraphic framework for the Santander Massif' metamorphic basement is here proposed. (C) Acad. Colomb. Cienc. Ex. Fis. Nat. 2016.
\end{abstract}

Key words: Colombia, Santander Massif, Silgara Formation, detrital zircons, Hf isotope geochemistry.

\section{Introducción}

La existencia de un adecuado marco estratigráfico es fundamental para develar con mayor precisión la historia geológica de una región y es la base para cualquier trabajo cartográfico-geológico y de correlación. Cuando se trabaja a escala regional con rocas de un basamento metamórfico, por razones propias de escala o debido a la imposibilidad de contar con estudios de mayor detalle, es fácil caer en la tentación de agrupar en una sola unidad a un amplio conjunto de litologías con una historia gelógica muy diferente. Por esta razón, agrupar litologías en una sola unidad, con base en una supuesta afinidad de sus condiciones metamórficas no es una tarea sufiente; también se requiere estudiar más detalladamente sus protolitos, en términos de su composición, proveniencia, contexto tectónico y máxima edad de depositación.

\footnotetext{
*Correspondencia:

Carlos Alberto García-Ramírez, cgarciar@uis.edu.co

Recibido: 5 de noviembre de 2015
}

Aceptado: 23 de mayo de 2016 
En el contexto antes referido, el estudio de los zircones detríticos (por ejemplo: mediante geocronología U-Pb y geoquímica isotópica del Hf) surge como una herramienta predilecta y eficaz, capaz de develar varios aspectos de la historia geológica de los protolitos de las rocas metamórficas. Este tipo de datos, además de contribuir a determinar la edad de las rocas fuentes de sedimentos (fuentes del protolito) y la edad máxima de depositación de éstos, también ayudan a identificar antiguos ciclos de compresión-erosión y extensión-depositación. En lo referente particularmente a los estudios de la composición isotópica del Hf en zircones ígneos detríticos, es importante subrayar que éstos han alcanzado gran relevancia en los últimos años, gracias a que aportan información relacionada con la fuente o la afinidad de sus magmas asociados (por ejemplo: es posible establecer si los zircones fueron formados a partir de magmas generados por fusión parcial del manto empobrecido-depleted mantle-; etc.). La gran utilidad de éste método en análisis de proveniencia de sedimentos y también en estudios paleo-geográficos, entre otros muchos campos, esta ampliamente demostrada (Scherer, et al., 2001; Veevers, et al., 2006; Nebel, et al., 2014; Yang, et al., 2015). Todas estas fortalezas mencionadas para esos métodos, son fundamentales en el momento de definir un adecuado y coherente marco estratigráfico para una región concreta.

En el marco de las ideas anteriormente mencionadas, se desarrolló el presente estudio con base en análisis de geoquímica de isótopos estables de $\mathrm{Hf}$ en zircones detríticos (y puntualmente análisis de geoquímica de roca total), con el propósito de aportar nuevas evidencias que apoyen la propuesta de escisón de la Formación Silgará (propuesta formulada en Mantilla, et al., 2016), en las siguientes tres unidades metamórficas: (a) Esquistos del Silgará (s.s.), (b) Esquistos del Chicamocha (nombre aún transitorio) y; (c) Filitas de San Pedro. Asimismo, en éste estudio se propone un nuevo marco estratigráfico para el basamento metamórfico del Macizo de Santander, a partir de la información geológica disponible en la literatura especializada.

\section{Antecedentes y contexto geológico}

El Sistema Andino de Colombia (SAC), al igual que los Andes de Mérida y Ecuador, hacen parte del denominado Bloque Andino (en términos de Pennington, 1981) ó Andes del Norte (en términos de Gansser, et al., 1973 y; Alemán y Ramos, 2000). El SAC se considera formado por la acreción de varios terrenos alóctonos, entre los cuales destaca (por su relación con el presente trabajo) el terreno Chibcha, por ser éste donde se localiza el Macizo de Santander (según Toussaint y Restrepo, 1976). Sin embargo, estudios recientes realizados por van der Lilej, et al., (2016), señalan que no existen evidencias de la aloctonía del denominado terreno Chibcha, por lo que el debate sobre el tema quedaría abierto. En el sentido de Cediel, et al., (2003), el Macizo de Santander se proyectaría en la Subplaca Maracaibo y parcialmente haría también parte del dominio de la Subplaca Continental Central (estos dos últimos, separadas por la Falla de Bucaramanga-Santa Martha).

Las rocas del basamento metamórfico del Macizo de Santander (MS), se han agrupado en las siguientes unidades litológicas: Gneis de Bucaramanga, Esquistos del Silgará (s.s.), Esquistos del Chicamocha (nombre interino o transitorio asignado preliminarmente a los esquistos aflorantes en la franja Pescadero-Aratoca), Ortogneis, y Filitas de San Pedro (Ward, et al., 1973; Clavijo, 1994; Royero y Vargas, 1999; Royero y Clavijo, 2001; Mantilla, et al., 2016). Todas estas litologías se consideran de edad pre-Devónico Medio, debido a que el registro sedimentario más antiguo del MS contiene fósiles de ésta edad, y es observado cubriendo localmente las unidades metamórficas citadas (Boinet, et al., 1985).

Con el propósito de contextualizar mejor la problemática geológica abordada en el marco del presente estudio, a continuación se presenta de manera resumida una descripción muy general de las diferentes unidades que conforman el basamento metamórfico del MS.

\section{Gneis de Bucaramanga}

Esta unidad se compone principalmente de gneises pelíticos y máficos, cuarcitas, mármoles, anfibolitas y localmente migmatitas. Las máximas condiciones del metamorfismo alcanzadas por esta unidad, se proyectan en la facies anfibolita alta (zona de la sillimanita). Los estudios geocronológicos realizados en litologías paragneisicas de ésta unidad, han permitido establecer que su protolito tiene una máxima edad de depositación del Meso-Proterozoico (edad de depositación entre $\sim 1200-1300 \mathrm{Ma}$; según edades U-Pb en zircones detríticos), y ha sido afectada por eventos metamórficos que guardan relación temporal con los reportados para el cinturón orogénico Grenvilliano que afectó al margen Este de Laurentia a finales del Meso-Proterozoico y comienzos del Neo-Proterozoico (entre $\sim 1100$ y $\sim 980 \mathrm{Ma}$; Cordani, et al., 2005).

\section{Esquistos de Silgara (s.s.)}

Esta unidad se compone principalmente de rocas metacuarzofeldespáticas (metaarensicas, cuarcitas, metagrauvacas) y metapelíticas (esquistos micáceos y filitas cloriticas), según ha sido documentada en Ward, et al. (1973) para su localidad tipo, localizada en la quebrada homónima (franja metamórfica Matanza-Cachirí). La máxima edad de depositación de ésta unidad (definida con base en muestras colectadas en inmediaciones a la localidad tipo), se considera de $\sim 900 \mathrm{Ma}$ (Neo-Proterozoico Temprano; según Mantilla, et al., 2016). La edad del evento metamórfico principal que afectó a estas litologías (facies esquistos verdes, zona del granate), posiblemente se relacione con el evento QuetameCaparonensis (según Restrepo-Pace y Cediel, 2010), también denominado Evento Orogénico Fammatiniano Principal 
(Mantilla, et al., 2016), el cual tuvo lugar durante el Ordovício Temprano ( 480-470 Ma; según van der Lilej, et al., 2016). Sin embargo, no se descarta que ésta unidad haya sufrido otros eventos de metamorfismo de más bajo grado, anteriores al Evento Orogénico Fammatiniano Principal.

\section{Esquistos de Chicamocha}

La unidad Esquistos del Chicamocha es un nombre tentativo dado a una sucesión de rocas metacuarzofeldespáticas (cuarcitas), metapeíticas (esquistos micaceos con granate, estaurolita, cianita/andalusita y sillimanita) y metabasitas, aflorantes en el cañón del río homónimo (por la vía que comunica los Municipios de Piedecuesta y Aratoca). Las litologías y las edades de los zircones detríticos de ésta unidad son muy diferentes a las reportadas para la unidad Esquistos del Silgará (s.s.), llegando su protolito a tener una máxima edad de depositación del Cámbrico Medio ( $500 \mathrm{Ma}$; Mantilla, et al., 2016). El máximo pico de metamorfismo de éstas litologías (en facies anfibolita, zona de la sillimanita; según Ríos, et al., 2013), se considera, como en el caso anterior, relacionado temporalmente con el Evento Orogénico Famatiniano principal.

\section{Ortogneis}

Esta unidad se compone principalmente de gneises cuarzofeldespáticos, localmente hornbléndicos; y algunos cuerpos lenticulares de anfibolitas. Estas litologías de origen fundamentalmente ígneo, se consideran que fueron emplazadas de manera sincrónica (sin-tectónica) con el desarrollo del metamorfismo que tuvo lugar durante el evento orogénico Fammatiniano Principal (hace 480-472 Ma, según RestrepoPace y Cediel, 2010; Mantilla, et al., 2012; Van der Lilej, 2013).

\section{Filitas de San Pedro}

Las Filitas del San Pedro se consideraban antes como parte constituyente de la Formación Silgará ó unidad Esquistos del Silgará s.l. (Mantilla, et al., 2016). La unidad Filitas de San Pedro es la unidad metamórfica más joven reconocida en el Macizo de Santander. La máxima edad de depositación de su protolito se considera en edad del Ordovícico Tardío (según edades $\mathrm{U}-\mathrm{Pb}$ de los zircones detríticos más jóvenes presentes en sus litologías siliciclásticas » $450 \mathrm{Ma}$ ). La edad del evento de metamorfismo que afectó a esta unidad no ha sido aún determinado por métodos geocronológicos, pero se considera que esta relacionada temporalmente con el Evento Orogénico Fammatiniano Menor, el cual tivo lugar a finales del Ordovício Tardío ( 450 Ma; en Mantilla, et al., 2016).

\section{Métodos analíticos}

Con el propósito de identificar posibles nuevas diferencias (ó similitudes), en términos de edades y composiciones isotópicas iniciales del $\mathrm{Hf}$ en zircones detríticos, entre las unidades escindidas de la Formación Silgará (Esquistos del Silgará s.s.; Esquistos del Chicamocha y; Filitas de San Pedro, según Mantilla, et al., 2016), se colectaron muestras de roca en las franjas Matanza-Cachirí (donde aflora la localidad tipo de la Formación Silgará; hoy denominda Esquistos del Silgará s.s.) y Piedecuesta-Aratoca (donde afloran las unidades Esquistos del Chicamocha y; Filitas de San Pedro).

Las extracción de zircones de las muestras colectadas (ver Tabla 1) se realizó utilizando los métodos tradicionales (resumidos en Mantilla, et al., 2013) en el laboratorio ZirChron LLC (Tucson, AZ), y sus dataciones U-Pb fueron realizadas en el laboratorio de geoquímica isotópica de la

Tabla 1. Localización de las muestras del basamento metamórfico del Macizo de Santander, colectadas para el presente estudio.

\begin{tabular}{|c|c|c|c|c|c|c|c|c|}
\hline \multirow{2}{*}{$\begin{array}{l}\text { Unidad estratigráfica/ } \\
\text { Muestra/Facies de Metamorfismo }\end{array}$} & \multicolumn{2}{|c|}{ Coordenadas* } & \multicolumn{3}{|c|}{ Coordenadas locales $* *$} & \multirow{2}{*}{$\begin{array}{l}\text { Localización } \\
\text { Geográfica }\end{array}$} & \multirow{2}{*}{$\begin{array}{l}\text { Tipo de } \\
\text { roca }\end{array}$} & \multirow{2}{*}{$\begin{array}{l}\text { Tipo de } \\
\text { Análisis }\end{array}$} \\
\hline & Latitud & Longitud & $\mathbf{X}$ & $\mathbf{Y}$ & $\mathrm{Z}$ (msnm) & & & \\
\hline $\begin{array}{l}\text { Unidad Esquistos del Silgará s.s. } \\
\text { PS-7-1 } \\
\text { (Facies Esquistos Verdes; } \\
\text { zona de la clorita) }\end{array}$ & 7¹8’05.00”' & $73^{\circ} 03^{\prime} 00^{\prime}$ & 1.299 .288 & 1.113 .461 & 1944 & $\begin{array}{l}\text { Vía Matanza-Santa } \\
\text { Cruz-Rionegro }\end{array}$ & Cuarcita & $\begin{array}{l}\text { U-Pb; Hf; } \\
\text { GRT* }^{*}\end{array}$ \\
\hline $\begin{array}{l}\text { Unidad Esquistos del Chicamocha } \\
\text { PS-4-1 y } \\
\text { PS-4-2 } \\
\text { (Facies Anfibolita; } \\
\text { zona de la estaurolita) }\end{array}$ & $6^{\circ} 47^{\prime} 48.0^{\prime \prime}$ & $73^{\circ} 00^{\prime} 47.1^{\prime \prime}$ & 1.243 .469 & 1.117 .667 & $\sim 887$ & $\begin{array}{l}\text { Vía Bucaramanga- } \\
\text { Aratoca } \\
\text { (Cañón del } \\
\text { Chicamocha) }\end{array}$ & $\begin{array}{l}\text { Cuarcita } \\
\text { Esquisto } \\
\text { Pelíticos }\end{array}$ & $\begin{array}{l}\text { U-Pb; Hf; } \\
\text { GRT } \\
\text { GRT }\end{array}$ \\
\hline $\begin{array}{l}\text { Unidad Esquistos del Chicamocha } \\
\text { PS-3-1 } \\
\text { (Facies Esquistos verdes; } \\
\text { zona de la biotita) }\end{array}$ & $6^{\circ} 41^{\prime} 53.44^{\prime \prime}$ & $73^{\circ} .0^{\prime} 50.43^{\prime \prime}$ & 1.232 .575 & 1.117 .594 & $\sim 1767$ & $\begin{array}{c}\text { Vía Bucaramanga- } \\
\text { Aratoca }\end{array}$ & $\begin{array}{l}\text { Esquisto } \\
\text { Pelítico }\end{array}$ & GRT \\
\hline $\begin{array}{l}\text { Unidad Filitas de San Pedro } \\
\text { PS-1-1 } \\
\text { (Facies sub- esquistos verdes) }\end{array}$ & 6०43’20.1”' & $73^{\circ} 01^{\prime} 07.0 ’$ & 1.235 .238 & 1.117.074 & $\sim 1770$ & $\begin{array}{c}\text { Vía Bucaramanga- } \\
\text { Aratoca (Sector Mesa } \\
\text { de San Pedro) }\end{array}$ & $\begin{array}{l}\text { Meta- } \\
\text { arenisca }\end{array}$ & $\begin{array}{l}\text { U-Pb; Hf; } \\
\text { GRT }\end{array}$ \\
\hline
\end{tabular}

* Coordenadas Datum WGS84 (EPSG 4326)

** Coordenadas Planas con Datum Bogotá (Bogotá 1975 / Colombia Bogotá zone (21897)

GRT*: Análisis de Geoquímica de roca total 
Universidad Estatal de Washington (WSU, USA), utilizando la técnica LA-ICP-MS (Laser Ablation Inductively Coupled Plasma Mass Spectrometry). Estas dataciones se realizaron siguiendo los procedimientos analíticos descritos por Chang, et al. (2006) y sus resultados analíticos se presentan en Mantilla, et al., (2016).

Los análisis isotópicos del $\mathrm{Hf}$ en los granos de zircones (objeto central del presente estudio), fueron realizados en la WSU (USA), usando un equipo tipo ThermoFinniganTM Neptune MC-ICP-MS. La ablación se realizó aproximadamente durante 30 segundos, para de esta manera evitar una profundización significativa del hueco realizado mediante la ablación (generalmente $<30 \mathrm{pm}$ de profundidad). Un detalle mayor sobre los equipos y los procedimientos seguidos durante estos análisis, se relacionan en Vervoort, et al., (2004). Como es evidente, los granos de zircones analizados mediante geoquímica isotópica del Hf, previamente habían sido datados, tal como se indicó en el párrafo anterior.

Algunos análisis geoquímicos en roca total de muestras colectadas en cada una de las tres unidades ya referidas, también fueron llevados a cabo, con el propósito de explorar e identificar algunas diferencias preliminares entre las tres unidades antes referidas, desde el punto de vista de su composición geoquímica. Estos análisis, se realizaron en los laboratorios Acme Analytical Laboratories Ltd., siguiendo las especificaciones ofrecidas en los paquetes analíticos con códigos 4AB1 (Whole Rock Analysis of Majors and Trace Elements). Las especificaciones de los procedimientos analíticos empleados, se documenta en la siguiente página web del mencionado laboratorio (http://acmelab.com/pdfs/ Acme_Price_Brochure.pdf).

\section{Resultados}

\section{Generalidades de las muestras analizadas}

Las muestras de rocas metamórficas seleccionadas (según unidad estratigráfica) para el presente estudio, se relacionan a continuación.

(a) Esquistos del Silgará s.s.: muestra PS-7-1 (cuarcita), colectada a lo largo de la carreteable que comunica los municipios de Matanza y Rionegro (Franja MatanzaCachirí); (b) Esquistos del Chicamocha: muestras PS-41 (cuarcita), PS-4-2 y PS-3-1 (esquistos pelíticos) y; (c) Filitas de San Pedro: muestra PS-1-1 (meta-arenisca). Las dos últimas muestras fueron colectadas a lo largo de la carretera que comunica la ciudad de Bucaramanga con Aratoca, donde afloran las rocas de la denominada franja metamórfica Aratoca-Pescadero (ver datos de localización en Tabla 1 y Figura 1).

En la franja de rocas Maranza-Cachirí (donde aflora la unidad Esquistos del Silgará s.s., y donde se colectó la muestra PS-7-1), se observa una alternancia de rocas metasiliciclásticas, principalmente cuarcitas y metareniscas, y rocas metapelíticas aproximadamente en igual proporción. Estas litologías son foliadas y finamente laminadas con bandas milimétricas. La foliación presenta una tendencia norte-sur, viéndose alterada por replegamientos. Mineralógicamente las rocas de esta franja constan de cuarzo, muscovita, clorita, biotita, granate, grafito, plagioclasa, feldespato potásico, y opacos como minerales principales. Como accesorios aparecen epidota, zircón, titanita y apatito. Las paragénesis reportadas en éstas rocas apuntan a que el metamorfismo de estas litologías alcanzaron condiciones de facies esquistos verdes (parte baja de la zona del granate, según Villamizar y Rueda, 2014).

En la franja de rocas Pescadero-Aratoca (donde aflora la unidad Esquistos del Chicamocha, y donde se colectaron las muestras PS-4-1, PS-4-2 y PS-3-1), se observan metapelitas, metapsamitas y metabasitas (esquistos anfibólicos y anfibolitas). Estos últimos, se presentan a manera de cuerpos intermitentes, intercalados hacia la parte media de la unidad con esquistos peliticos. La muestra de cuarcita muestreada (materiales metapsamíticos), presenta mayoritariamente cuarzo, plagioclasa, microclina, cantidades variables y subordinadas de muscovita, biotita y granate como minerales principales. Los minerales menores son grafito, ilmenita, magnetita. Accesorios comunes son zircón, apatito, turmalina y rutilo. Las paragénesis reportadas en éstas rocas (García y Ríos, 1999; Ríos, et al, 2003; García y Ríos, 2004), apuntan a que el metamorfismo de estas litologías alcanzó condiciones de facies esquistos verdes, transición epidota - anfibolita y anfibolita (zona estaurolita-cianita).

En la misma franja de rocas antes referida (donde también aflora la unidad Filitas de San Pedro, y donde se colectó la muestra PS-1-1), se observa una sucesión de filitas cloríticas con foliación continua y fina, intercaladas con metaareniscas y meta-limolitas con débil foliación espaciada. Las meta-areniscas estudiadas, constan de cuarzo, muscovita, clorita, plagioclasa y feldespato potásico como minerales principales. La textura predominante es lepidogranoblástica. Otros minerales presentes son opacos, zircón, apatito. Las paragénesis reportadas en éstas rocas apuntan a condiciones de facies sub-esquistos verdes (Ríos, et al, 2003; García y Ríos, 2004).

\section{Datos de Geoquímica de Roca Total (GRT)}

Cuatro (4) muestras de rocas metamórficas fueron colectadas y analizadas mediante GRT (Tabla 2), tal como ya se mencionó anteriormente.

Los estudios geoquímicos de todas las cuatro muestras analizadas (PS-1-1, PS-3-1, PS-4-2, PS-7-1), pertenecientes a las tres unidades escindidas de la Formación Silgará, muestran diferencias que podrían ser explicadas por el origen del protolito. El contenido de $\mathrm{SiO}_{2}$ marca buena diferencia entre los esquistos pelíticos (PS-3-1 y PS-4-2; Unidad Esquistos del Chicamocha) y la metaarensica y cuarcita de las restantes dos unidades (PS-1-2 y PS-7-1). En las primeras 


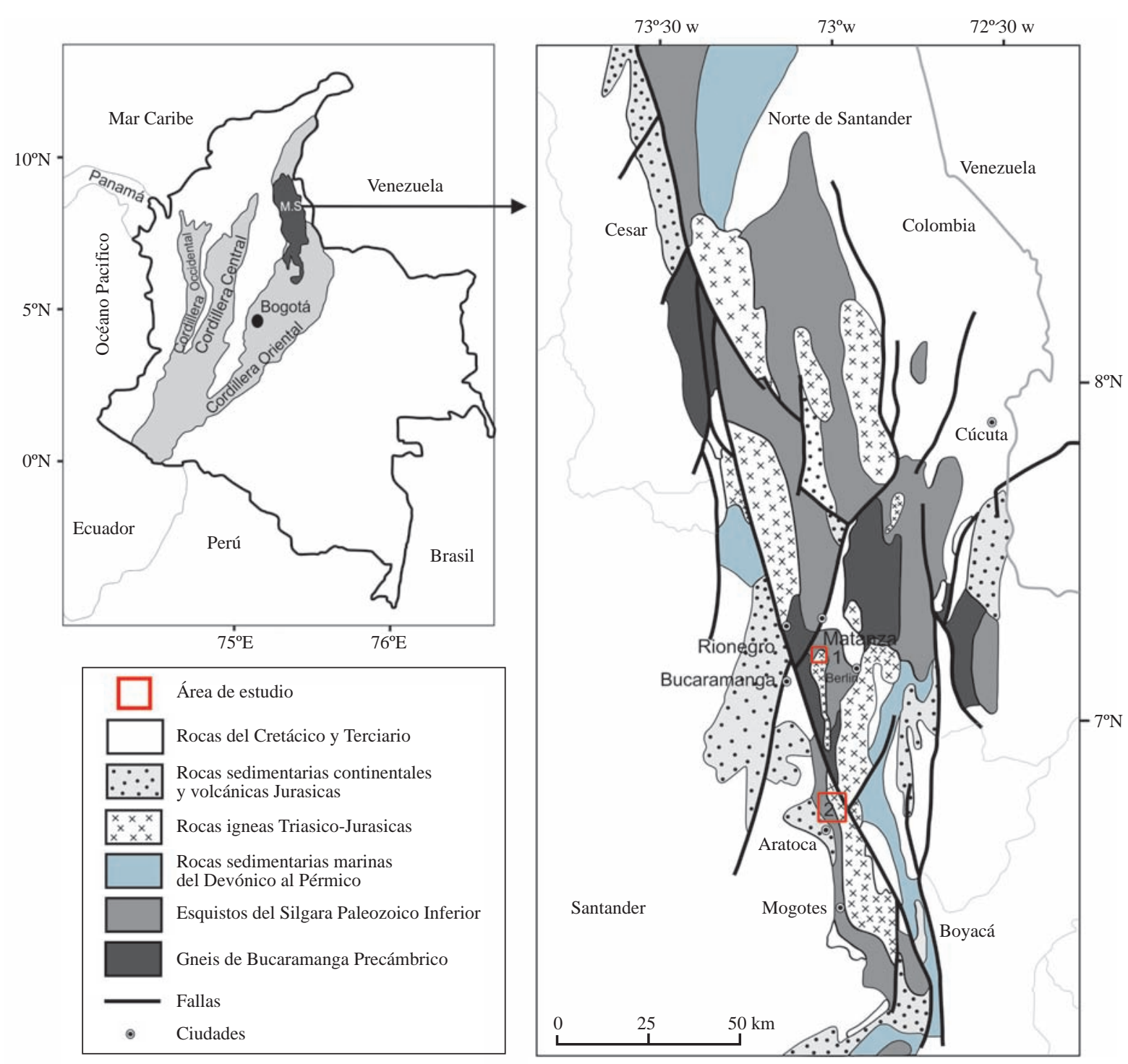

Figura 1. Esquema geológico del Macizo de Santander (Cordillera Oriental de Colombia), en el cual se resaltan las áreas muestreadas para análisis de isótopos de $\mathrm{Hf}$ en zircones detríticos en cuarcitas, y para estudios de geoquímica de roca total. Modificado de Goldsmith et al., (1971). El recuadro 1 se proyecta en la franja de rocas metamórficas Matanza-Cachirí, y el recuadro 2 en la franja Pescadero-Aratoca.

éste varia de 59.64 a $64.7 \%$ en peso, mientras que en las ultimas es 70.49 a $76.92 \%$ en peso. Como es de esperarse, el $\mathrm{Al}_{2} \mathrm{O}_{3}$ es más alto en las metapelitas (esquistos): 18.62$19.7 \%$ en peso, en comparación con las metaarensicas: 11.17 - $13.69 \%$. El contenido de $\mathrm{MgO}$ y $\mathrm{CaO}$ es bajo, variando entre $0.62-2.41$ y $0.03-1.11 \%$ en peso. La relación $\mathrm{K}_{2} \mathrm{O}$ / $\mathrm{Na}_{2} \mathrm{O}$ es baja para todas las rocas 1-2.45, excepto la muestra PS-3-1 que es de 8.63, lo cual se evidencia mediante el alto contenido de muscovita y biotita en esta roca.

En lo referente al patrón de los Elementos de Tierras Raras (REE: Rare Earth Elements; diagramas no incluidos), normalizados al Manto Primitivo (según datos reportados en Taylor y McLennan, 1995), estos muestran ser prácticamente similares, con enriquecimiento de las LREE (Light Rare Earth Elements) y empobrecimiento progresivo de las
HREE (Heavy Rare Earth Elements). En todas las muestras es característica la anomalía negativa en Eu, siendo la relación $\mathrm{Eu} / \mathrm{Eu}^{*}$ de 0.17 para la muestra PS-1-1; 0.81 en la muestra PS-3-1; 0.59 en la muestra PS-4-2 y 0.68 en la muestra PS-7-1.

Se graficaron los contenidos de elementos traza y algunas ETR, usando el diagrama araña (también referido en la bibliografía como aracnigrama) con los contenidos normalizados a la composición media de la corteza (Weaver y Tarney, 1984). De acuerdo con esta normalización (ver Figura 2), se observa que los patrones de distribución y contenidos son muy similares en las muestras PS-4-2 y PS7-1. La muestra PS-1-1 (Filitas de San Pedro) evidencia presencia de minerales o material ligeramente más máficos, en comparación con las muestras PS-4-2 y PS-7-1. 
Tabla 2. Composición química de las rocas estudiadas.

\begin{tabular}{|c|c|c|c|c|}
\hline Muestra & PS-1-1 & PS-3-1 & PS-4-2 & PS-7-1 \\
\hline Unidad & Filitas de San Perdo & Esquistos Chicamocha & Esquistos Chicamocha & Esquistos del Silgará \\
\hline $\mathrm{SiO}_{2}$ & 76,92 & 64,7 & 59,64 & 70,49 \\
\hline $\mathrm{TiO}_{2}$ & 0,39 & 0,9 & 0,85 & 0,71 \\
\hline $\mathrm{Al}_{2} \mathbf{O}_{3}$ & 11,17 & 18,62 & 19,17 & 13,69 \\
\hline $\mathrm{Fe}_{2} \mathrm{O}_{3}$ & 3,98 & 5,38 & 3,21 & 2,61 \\
\hline $\mathrm{FeO}$ & 1,66 & 0,94 & 5,2 & 2,64 \\
\hline MnO & 0,02 & $<0.01$ & 0,22 & 0,11 \\
\hline MgO & 0,71 & 0,62 & 2,41 & 1,39 \\
\hline $\mathrm{CaO}$ & 0,13 & 0,03 & 0,67 & 1,11 \\
\hline $\mathrm{Na}_{2} \mathrm{O}$ & 1,57 & 0,56 & 1,52 & 2,51 \\
\hline $\mathbf{K}_{2} \mathbf{O}$ & 1,92 & 4,4 & 3,73 & 2,51 \\
\hline $\mathbf{P}_{2} \mathbf{O}_{5}$ & 0,07 & 0,16 & 0,12 & 0,13 \\
\hline LOI & 1,2 & 3,3 & 3 & 1,9 \\
\hline $\mathrm{Cr}_{2} \mathrm{O}_{3}$ & 0,006 & 0,009 & 0,015 & 0,008 \\
\hline Total & 99,746 & 99,619 & 99,755 & 99,808 \\
\hline Mo & 0,7 & 0,6 & 0,5 & 0,6 \\
\hline Ni & 23 & 24 & 57 & $<20$ \\
\hline $\mathrm{Ni}$ & 27,9 & 21,3 & 54,5 & 17 \\
\hline $\mathrm{Zn}$ & 92 & 67 & 109 & 85 \\
\hline $\mathrm{Cu}$ & 7 & 22 & 42,5 & 25,8 \\
\hline As & $<0.5$ & $<0.5$ & 16,3 & $<0.5$ \\
\hline Cd & $<0.1$ & $<0.1$ & $<0.1$ & $<0.1$ \\
\hline Sb & $<0.1$ & $<0.1$ & $<0.1$ & $<0.1$ \\
\hline $\mathbf{B i}$ & $<0.1$ & 0,2 & 0,3 & $<0.1$ \\
\hline Ag & $<0.1$ & $<0.1$ & $<0.1$ & $<0.1$ \\
\hline Au & 0,5 & $<0.5$ & $<0.5$ & $<0.5$ \\
\hline Hg & $<0.01$ & $<0.01$ & $<0.01$ & $<0.01$ \\
\hline $\mathbf{T l}$ & $<0.1$ & $<0.1$ & 0,1 & 0,1 \\
\hline Se & $<0.5$ & $<0.5$ & $<0.5$ & $<0.5$ \\
\hline Ga & 12,7 & 24,2 & 24,8 & 17,1 \\
\hline Sc & 6 & 14 & 19 & 11 \\
\hline $\mathbf{V}$ & 53 & 106 & 125 & 63 \\
\hline $\mathbf{W}$ & 0,9 & 2,2 & 3,1 & 0,8 \\
\hline Co & 10,6 & 6,1 & 28,9 & 8,8 \\
\hline Cs & 3 & 5,1 & 2,5 & 1,3 \\
\hline $\mathbf{B a}$ & 1004 & 1733 & 434 & 493 \\
\hline $\mathbf{B e}$ & $<1$ & 2 & $<1$ & 1 \\
\hline $\mathbf{R b}$ & 68,1 & 144,5 & 116,7 & 83,9 \\
\hline Sn & $<1$ & 2 & 5 & 2 \\
\hline Th & 7,7 & 12,7 & 14,4 & 14,9 \\
\hline $\mathbf{N b}$ & 7,9 & 16,5 & 15,8 & 14,4 \\
\hline Ta & 0,6 & 1,3 & 1 & 0,9 \\
\hline
\end{tabular}




\begin{tabular}{|c|c|c|c|c|}
\hline Muestra & PS-1-1 & PS-3-1 & PS-4-2 & PS-7-1 \\
\hline Unidad & Filitas de San Perdo & Esquistos Chicamocha & Esquistos Chicamocha & Esquistos del Silgará \\
\hline $\mathrm{Sr}$ & 48,3 & 183,4 & 92,4 & 134,5 \\
\hline $\mathrm{Zr}$ & 165,7 & 273,1 & 158,2 & 364,6 \\
\hline Hf & 4,2 & 7,4 & 4,3 & 10,5 \\
\hline $\mathbf{Y}$ & 20,4 & 39,9 & 41,9 & 35,5 \\
\hline $\mathbf{P b}$ & 1,8 & 1,4 & 5,5 & 8,3 \\
\hline $\mathbf{U}$ & 1,5 & 3,1 & 2,4 & 2,9 \\
\hline $\mathbf{L a}$ & 21,4 & 200,3 & 44,1 & 44,2 \\
\hline Ce & 44,3 & 120,7 & 83,9 & 90,1 \\
\hline Pr & 5,35 & 44,9 & 10,58 & 10,42 \\
\hline Nd & 20,6 & 159,1 & 39,6 & 39,4 \\
\hline Sm & 3,97 & 26,14 & 8,41 & 7,64 \\
\hline $\mathbf{E u}$ & 1,07 & 5,59 & 1,64 & 1,65 \\
\hline Gd & 4,27 & 16,99 & 8,53 & 7,16 \\
\hline $\mathbf{T b}$ & 0,64 & 2,24 & 1,37 & 1,05 \\
\hline Dy & 4,2 & 11,73 & 7,42 & 6,31 \\
\hline Ho & 0,8 & 1,59 & 1,49 & 1,29 \\
\hline Er & 2,09 & 3,8 & 4,11 & 3,81 \\
\hline Tm & 0,3 & 0,57 & 0,62 & 0,53 \\
\hline $\mathbf{Y b}$ & 2,32 & 3,55 & 3,94 & 3,69 \\
\hline Lu & 0,32 & 0,47 & 0,62 & 0,52 \\
\hline
\end{tabular}

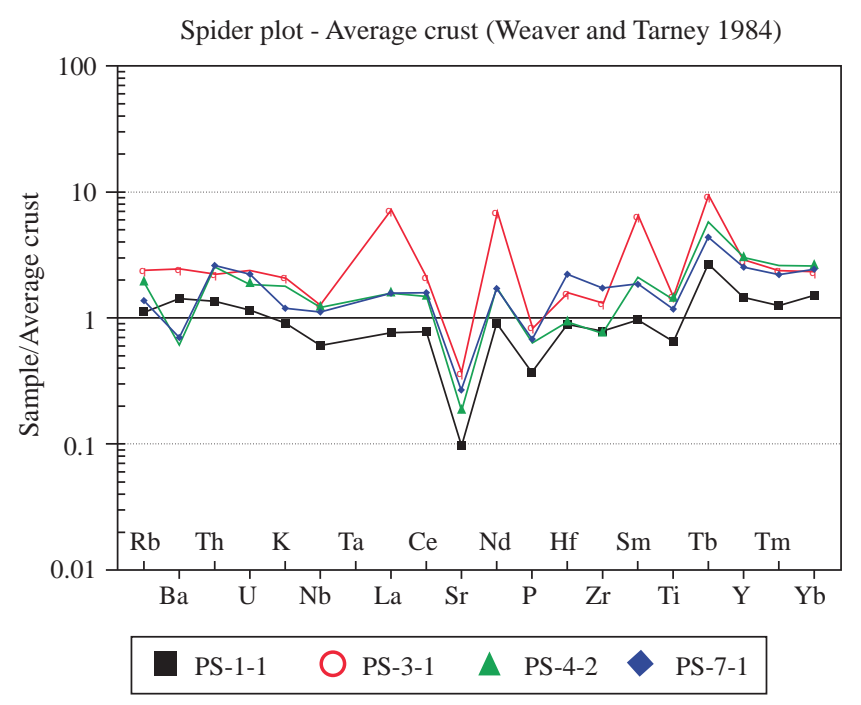

Figura 2. Diagrama Araña para las muestras estudiadas. Contenidos normalizados al promedio de la corteza de Weaver and Tarney (1984).

El enriquecimiento en ETR (La, Nd, Sm, Yb) en el esquisto biotitico analizado de de la unidad Esquistos del Chicamocha (muestra PS-3-1), podría explicarse a partir de la presencia de esfena y monazita. Los contenidos de los elementos menos móviles indican una procedencia de los sedimentos con fuerte aporte por erosión de una corteza continental bastante diferenciada. No obstante, la distribución de los diagramas araña relacionados en la Figura 2, distribuidos entorno a 1 (normalización respecto a la corteza terrestre), permiten señalar claramente que la fuente de éstos sedimentos proceden de la erosión de una corteza continental, cuya composición promedio es andesítica.

Aunque se requiere de una mayor densidad de muestreo, es posible resaltar en términos generales, que las rocas metamorficas agrupadas dentro de las Filitas de San Pedro (por ejemplo: muestra PS-1-1), indican algunos ligeros aportes de una fuente máfica (de una corteza comparativamente menos diferenciada). Por otro lado, la muestra PS-4-1 (Esquistos del Chicamocha), sugiere que su protolito deriva de una corteza continental bastante diferenciada, en comparación con la muestra PS-7-1 (Esquistos del Silagrá s.s.).

\section{Datos isotópicos Lu-Hf en zircones detríticos}

Un total de veinticinco (25) granos de zircones fueron seleccionados para el análisis de la composición isotópica del Hf, del total de las tres muestras colectadas: PS-7-1 (cuarcita de los Esquistos del Silgará), PS-4-1 (cuarcita de los Esquistos del Chicacmocha) y; PS-1-1 (metaarensica de la Filitas de San Pedro). 
El número de granos seleccionados fue relativamente bajo, debido a que se intentó seleccionar aquellos cristales de zircones con los tamaños más adecuados, de tal manera que se pudiera realizar el punto de análisis isotópico para Hf, en proximidad (y en la misma zona) al punto de análisis hecho previamente para U-Pb. Los datos derivados de los análisis isotópicos de Lu-Hf, se resumen en la Tabla 3, y las graficas en las cuales estos datos fueron proyectados, se presentan en la Figura 3.

A continuación se presentan los resultados obtenidos para cada una de las unidades referidas.

\section{Unidad Esquistos del Silgará s.s.}

En la muestra PS-7-1 (cuarcita) de ésta unidad, se seleccionaron ocho (8) granos de zircones detríticos, y éstas fueron sus edades $\mathrm{U}-\mathrm{Pb}$ obtenidas previamente (de más antigua a más joven): $1672 \pm 21,8 \mathrm{Ma}, 1476 \pm 19,3 \mathrm{Ma}, 1414 \pm 18,7 \mathrm{Ma}$, $1289 \pm 16,9 \mathrm{Ma}, 1000 \pm 13,1 \mathrm{Ma}, 975 \pm 12,8 \mathrm{Ma}, 965 \pm 13,1$ Ma y $881 \pm 22,5 \mathrm{Ma}$ (ver Tabla 3; mayor detalle de dataciones en Mantilla, et al., 2016). Las edades U-Pb aquí referidas, se proyectan en la concordia (Mantilla, et al., 2016), lo que permite establecer que no presentan pérdidas de $\mathrm{Pb}$ (evidencia que el sistema ha permanecido cerrado desde su cristalización).

Tabla 3. Resultados analíticos Lu/Hf a partir de zircones detríticos presentes en muestras de metaareniscas y cuarcitas y sus respectivos valores epsilón (عHft). Macizo de Santander, Cordillera Oriental de Colombia.

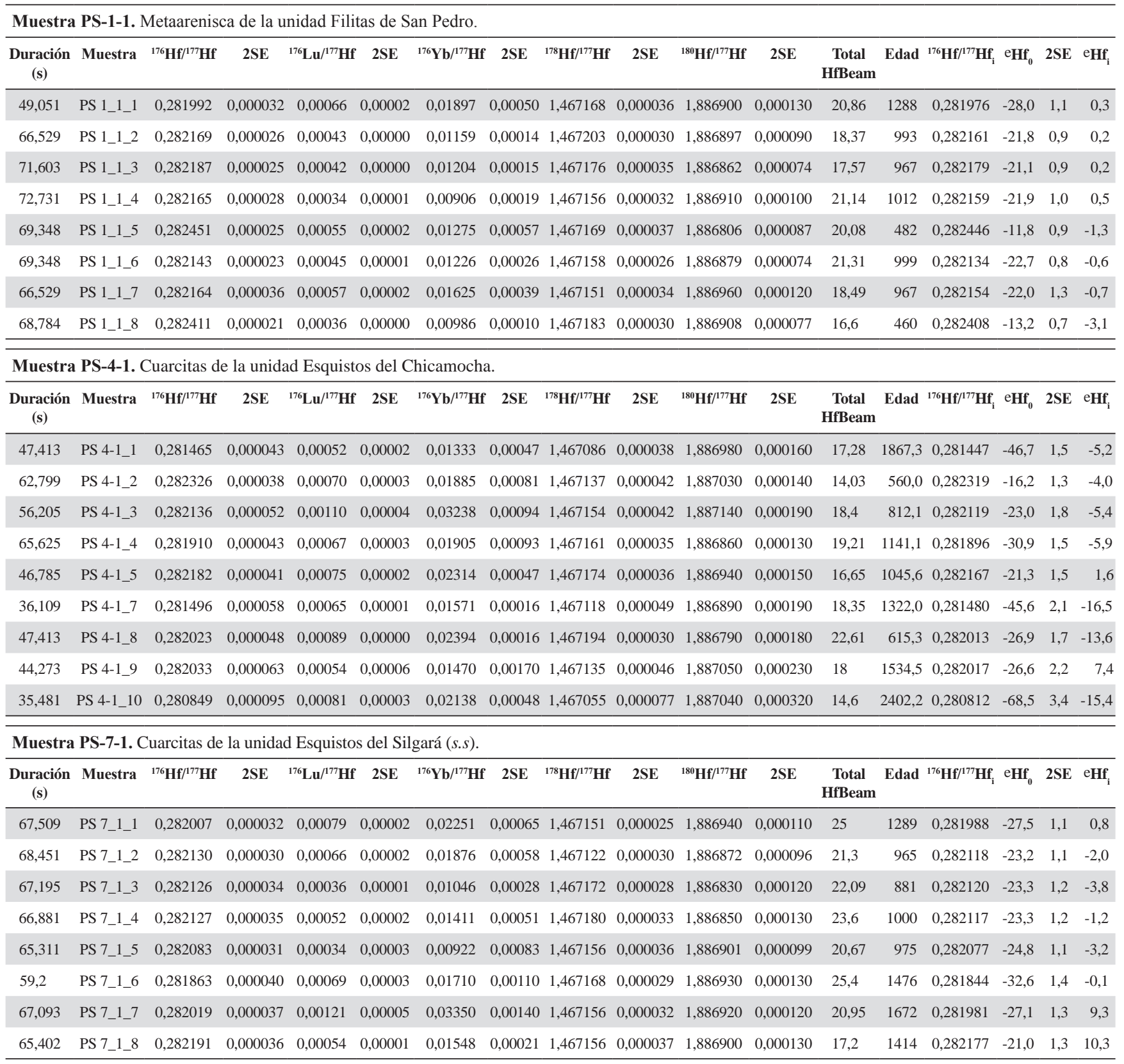




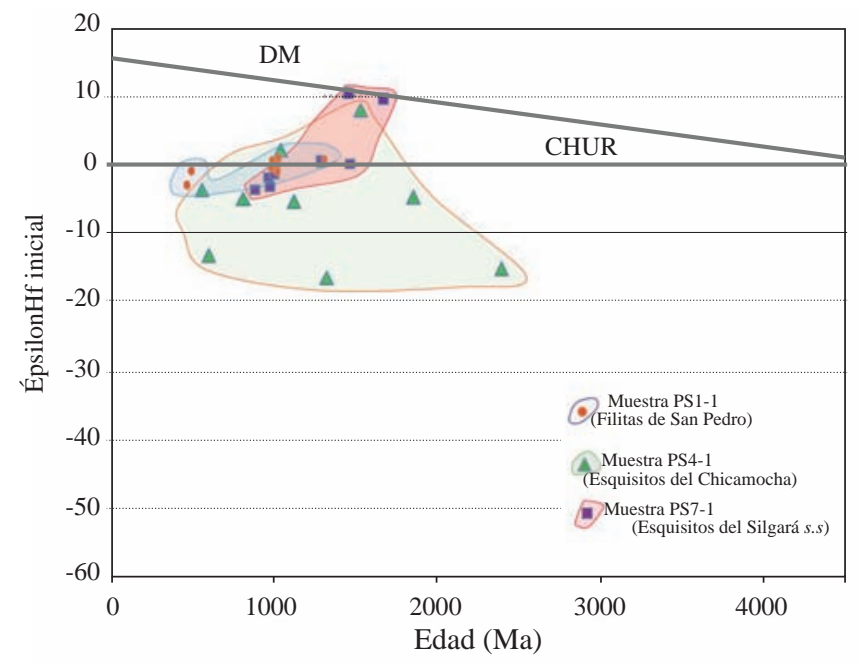

Figura 3. Valores Épsilon Hf inicial $\left(\mathrm{eHf}_{\text {(inicial) }}\right.$ ) obtenidos a partir de zircones detríticos presentes en las unidades metamórficas del Macizo de Santander (La muestra PS-7-1 fue colectada en la Franja Matanza-Cachirí; y las muestras PS-4-1 y PS-1-1 en la franja Pescadero-Aratoca). Las líneas de evolución de la composición isotópica del Hf para las cortezas de las edades referidas se apoyan en datos resumidos en Turkina et al., 2014

Los valores de las relaciones ${ }^{176} \mathrm{Lu} /{ }^{177} \mathrm{Hf}$ en cada uno de los granos de zircones antes referidos (respecto a su correspondiente edad U-Pb), son los siguientes: 0,00121 ( 1672Ma); 0,00069 ( 1476 Ma); 0,00054 ( 1414 Ma); 0,00079 ( 1289 Ma); 0,00052 ( 1000 Ma); 0,00034 ( 975 Ma); 0,00066 ( 965 Ma) y; 0,00036 ( 881 Ma). Los correspondientes valores iniciales de ${ }^{176} \mathrm{Hf} /{ }^{177} \mathrm{Hf}$ son respectivamente los siguientes: 0,281981 ( 1672Ma); 0,281844 ( 1476 Ma); 0,282177 ( 1414 Ma); 0,281988 ( 1289 Ma); 0,282117 ( 1000 Ma); 0,282077 ( 975 Ma); 0,282118 ( 965 Ma) y; 0,282120 ( $\sim 881 \mathrm{Ma})$. En este contexto, los valores $\varepsilon \mathrm{Hf}$ iniciales calculados para cada una de las edades de los zircones detríticos analizados, arrojaron valores tanto negativos, como positivos. Estos valores son los siguientes: $\mathrm{eHf}_{1672 \mathrm{Ma}}=+9.3$; $\mathrm{eHf}_{1476 \mathrm{Ma}}=-0.1, \mathrm{eHf}_{1414 \mathrm{Ma}}=+10.3, \mathrm{eHf}_{1289 \mathrm{Ma}}=+0.8, \mathrm{eHf}_{1000 \mathrm{Ma}}=$ 1.2, eHf $_{975 \mathrm{Ma}}=-3.2, \mathrm{eHf}_{965 \mathrm{Ma}}=-2.0, \mathrm{eHf}_{881 \mathrm{Ma}}=-3.8$ (ver Tabla 3).

\section{Unidad Esquistos del Chicamocha}

En la muestra PS-4-1 (cuarcita) de ésta unidad, se seleccionaron nueve (9) granos de zircones detríticos, y éstas fueron sus edades U-Pb obtenidas previamente (de más antigua a más joven): 2402,2 $\pm 10,7 \mathrm{Ma} ; 1867,3 \pm 10,5$ Ma; $1534,5 \pm 11,1 \mathrm{Ma} ; 1322 \pm 16,1 \mathrm{Ma} ; 1141,1 \pm 12,5 \mathrm{Ma}$; $1045,6 \pm 14,2 \mathrm{Ma} ; 812,1 \pm 10 \mathrm{Ma} ; 615,3 \pm 6,6 \mathrm{Ma} \mathrm{y;} \mathrm{560 \pm 6,6}$ Ma (ver Tabla 3; mayor detalle de las dataciones en Mantilla, et al., 2016). Las edades U-Pb aquí referidas, se proyectaron en la concordia, es decir, se concluye que estos no presentan pérdidas de $\mathrm{Pb}$ (Mantilla, et al., 2016).

Los valores de las relaciones ${ }^{176} \mathrm{Lu} /{ }^{177} \mathrm{Hf}$ en cada uno de los granos de zircones antes referidos (respecto a su correspondiente edad U-Pb), son los siguientes: 0,00081
( 2402,2 Ma); 0,00052 ( 1867,3 Ma); 0,00054 ( 1534,5 $\mathrm{Ma}) ; 0,00065$ ( 1322 Ma); 0,00067 ( 1141,1 Ma); 0,00075 $(\sim 1045,6 \mathrm{Ma}) ; 0,00110 \quad(\sim 812,1 \mathrm{Ma}) ; 0,00089$ ( 615,3 Ma) y; 0,00070 ( 560 Ma). Los correspondientes valores iniciales de ${ }^{176} \mathrm{Hf} /{ }^{177} \mathrm{Hf}$ son respectivamente los siguientes: 0,280812 ( 2402,2 Ma); 0,281447 ( 1867,3 Ma); 0,282017 ( 1534,5 Ma); 0,281480 ( 1322 Ma); 0,281896 ( 1141,1 $\mathrm{Ma}) ; 0,282167$ ( 1045,6 Ma); 0,282119 ( 812,1 Мa); 0,282013 ( 615,3 Ma) y; 0,282319 ( 560 Ma). Los valores $\varepsilon$ Hf iniciales calculados para cada una de las edades de los zircones detríticos analizados, arrojaron valores tanto negativos, como positivos. Estos valores son los siguientes: $\mathrm{eHf}_{2402,2 \mathrm{Ma}}=+15,4 ; \mathrm{eHf}_{1867,3 \mathrm{Ma}}=-5,2 ; \mathrm{eHf}_{1534,5 \mathrm{Ma}}=+7,4 ; \mathrm{eHf}_{1322}$ $=+16,5 ; \mathrm{eHf}_{1141,1 \mathrm{Ma}}=-5,9 ; \mathrm{eHf}_{1045,6 \mathrm{Ma}}=+1,6 ; \mathrm{eHf}_{812,1 \mathrm{Ma}}=-5,4$; $\mathrm{eHf}_{615,3 \mathrm{Ma}}=+13,6$; $\mathrm{eHf}_{560 \mathrm{Ma}}=-4,0$ (ver Tabla 3).

\section{Unidad Filitas de San Pedro}

En la muestra PS-1-1 (metaarensica) de ésta unidad, se seleccionaron ocho (8) granos de zircones detríticos, los cuales presentan las siguientes edades (de más antigua a más joven): $1288,5 \pm 9,6 \mathrm{Ma}, 1012,3 \pm 13,4 \mathrm{Ma}, 999,4 \pm 14,6 \mathrm{Ma}$, $993,1 \pm 14,25 \mathrm{Ma}$, dos granos con edades de 966,5 $\pm 20,6 \mathrm{Ma}$, 481,5 $\pm 6,5$ Ma y, 457? $\pm 6,9$ Ma (ver Tabla 3; mayor detalle de las dataciones en Mantilla, et al., 2016). Las edades $\mathrm{U}-\mathrm{Pb}$ aquí referidas, al igual que en los anteriores casos, se proyectan en la concordia (Mantilla, et al., 2016).

Los valores de las relaciones ${ }^{176} \mathrm{Lu} /{ }^{177} \mathrm{Hf}$ en cada uno de los granos de zircones antes referidos (respecto a su correspondiente edad U-Pb), son los siguientes: 0,00066 ( 1288 Ma), 0,00034 ( 1012 Ma), 0,00045 ( 999 Ma), 0,00043 ( 993 Ma), 0,00042 ( 967 Ma), 0,00057 ( 967 Ma), 0,00055 ( 482 Ma) y, 0,00036 ( 460 Ma). Los correspondientes valores iniciales de ${ }^{176} \mathrm{Hf} /{ }^{177} \mathrm{Hf}$ son respectivamente los siguientes: 0,281976 ( 1288 Ma), 0,282159 ( 1012 Ma), 0,282134 ( 999 Ma), 0,282161 ( 993 Ma), 0,282179 ( 967 Ma), 0,282154 ( 967 Ma), 0,282446 ( 482 Ma) y, 0,282408 ( 460 Ma). Los valores $\varepsilon$ Hf iniciales calculados para cada una de las edades de los zircones detríticos analizados, arrojaron valores tanto negativos, como positivos. Estos valores son los siguientes: $\mathrm{eHf}_{1288 \mathrm{Ma}}=+0,3 ; \quad \mathrm{eHf}_{1012 \mathrm{Ma}}=+0,5 ; \quad \mathrm{eHf}_{999 \mathrm{Ma}}=-0,6 ; \quad \mathrm{eHf}_{993}$ $\mathrm{Ma}=+0,2 ; \mathrm{eHf}_{967 \mathrm{Ma}}=+0,2 ; \mathrm{eHf}_{967 \mathrm{Ma}}=-0,7 ; \mathrm{eHf}_{482 \mathrm{Ma}}=-1,3 ; \mathrm{eHf}_{460}$ $\mathrm{Ma}=-3,1$ (ver Tabla 3).

\section{Consideraciones previas y significado de los valores isotópicos del $\mathrm{Lu}-\mathrm{Hf}$}

Los zircones son minerales adecuados para estudios de isótopos de Hf en rocas antiguas. Estos tienen alta concentraciones de Hf, bajas relaciones Lu/Hf, y pueden ser datados de manera precisa mediante técnicas U-Pb. Esos datos son importantes, dado que ayudan a determinar si el mineral se ha mantenido como un sistema abierto o cerrado. Por otro lado, el zircón es un mineral muy resistente, lo que le da la particularidad de sobrevivir a la erosión o el metamorfismo, los cuales pueden destruir o modificar las 
rocas que lo hospedan. Por esta razón, los zircones han sido usados exitosamente en muchos estudios de isótopos de $\mathrm{Hf}$ (Amelin, et al., 1999; Andres, et al., 2004; Siebel y van den Haute, 2007; Restrepo-Moreno, 2009; Hoang, et al., 2009; Zeh, et al., 2009; Arvizu y Iriondo, 2011; Zeh, et al., 2013; Turkina, et al., 2014).

El valor de la notación épsilon $\mathrm{Hf}$ inicial $\left(\mathrm{eHf}_{\mathrm{i}}\right)$, se determina mediante la siguiente relación:

$\mathrm{eHf}_{(\mathrm{t})}=\left({ }^{176} \mathrm{Hf} /{ }^{177} \mathrm{Hf} f_{\text {muestra(t) }}{ }^{176} \mathrm{Hf} /{ }^{177} \mathrm{Hf} \mathrm{CHUR}(\mathrm{t})-1\right) \times 10^{4}$ (Scherer, et al., 2001),

donde (t) es la edad geológica de la muestra y, ${ }^{176} \mathrm{Hf} /{ }^{177} \mathrm{Hf}$ CRUR(t) es la composición isotópica del CHUR (Chondritic Uniform Reservoir) en un tiempo $t$. El CHUR se asume como el material primitivo del sistema solar en su etapa temprana (Blichert-Toft y Albarède, 1997; Machado y Simonetti, 2001; Scherer, et al., 2001; Albarède, et al., 2006; Bouvier, et al., 2008). Según Blichert-Toft y Albarède (1997) y Machado y Simonetti (2001), la variación temporal en la relación ${ }^{176} \mathrm{Hf} /{ }^{177} \mathrm{Hf} \mathrm{CHUR}_{(t)}$ a través del tiempo geológico, esta definida por el valor ${ }^{176} \mathrm{Hf} /{ }^{177} \mathrm{Hf}=0.0332 \pm 2$; y un valor presente ${ }^{176} \mathrm{Hf} /{ }^{177} \mathrm{Hf}=0.282772 \pm 29$ (valor inicial para el material del sistema solar a los $4.56 \mathrm{Ga}$ de ${ }^{176} \mathrm{Hf} /{ }^{177} \mathrm{Hf}=0.279742 \pm 29$ ).

Debido a las particularidades antes referidas, la sistemática Lu-Hf en zircones es una herramienta de gran utilidad para entender el desarrollo de la diferenciación Manto/Corteza. Según Siebel y van den Haute (2007), los zircones con valores Epsilo $\mathrm{Hf}(\mathrm{t})$ positivos indican que estos fueron cristalizados a partir de magmas de afinidad juvenil (por ejemplo: magmas silicatados originados en el manto empobrecido). Contrariamente, aquellos zircones con valores Epsilo Hf(t) negativos, pueden ser interpretados como derivados de la cristalización de magmas con una afinidad propia de la refusión de arcos corticales antiguos (re-trabajados) ó debido a procesos de contaminación de magmas juveniles con material cortical, a consecuencia del ascenso-estancamientoascenso de estos fundidos durante su paso por la corteza (Amelin, et al., 1999; Kemp, et al., 2005; Siebel y van den Haute, 2007; Koglin, et al., 2010; Turkina, et al., 2014). Sin embargo, es importante tener presente que existen varios problemas de carácter interpretativo sino se tiene en cuenta las diferentes particularidades de los circones al momento de ser datados y al momento de ser analizados mediante geoquímica de Hf (Vervoort and Kemp, 2016).

En el contexto antes referido, se evidencia que los zircones ígneos detríticos presentes en las cuarcitas analizadas de la unidad Esquistos del Silgará (s.s.), aflorantes en la franja de rocas metamórficas Matanza-Cachirí (muestra PS-71), proceden del desmantelamiento (erosión) de arcos magmáticos (o por la re-depositación, durante un segundo ciclo o más) formados principalmente por magmas de afinidad juvenil; los cuales debieron formarse durante el Paleo-Proterozoico Tardío y Meso-Proterozoico, más concretamente durante el Estatérico $\left(\mathrm{eHf}_{1672 \mathrm{Ma}}=+9.3\right.$;
Paleo-Proterozoico Tardío), Calímico $\left(\mathrm{eHf}_{1414 \mathrm{Ma}}=+10.3\right.$; Meso-Proterozoico) y parcialmente (?) también aquellos del Ectásico $\left(\mathrm{eHf}_{1289 \mathrm{Ma}}=+0.8\right.$; Meso-Proterozoico); y también por arcos magmáticos formados posiblemente a partir de magmas inicialmente de afinidad juvenil, aunque afectados por contaminación cortical (o simplemente a partir de magmas con una afinidad de arcos magmáticos antiguos retrabajados); $\mathrm{eHf}_{1000 \mathrm{Ma}}=-1.2, \mathrm{eHf}_{975 \mathrm{Ma}}=-3.2, \mathrm{eHf}_{965 \mathrm{Ma}}=-2.0$, $\mathrm{eHf}_{881 \mathrm{Ma}}=-3.8$ ), formados principalmente durante el Tónico (Neo-Proterozoico Temprano).

Los valores (eHf) de los zircones ígneos detríticos presentes en las cuarcitas aflorantes en la franja Pescadero-Aratoca (denominada de manera interina como unidad Esquistos del Chicamocha), permiten sugerir que éstos también evidencian una proveniencia de arcos magmáticos formados principalmente por magmas de afinidad juvenil (Depleted Mantle-Related), relacionados con el desmantelamiento de arcos magmáticos de edad Paleo-Proterozoico (Sidérico; $\mathrm{eHf}_{2402,2 \mathrm{Ma}}=+15$ ) y Meso-Proterozoico (Calímico: eHf $\mathrm{Ma}=+7,4$; Ectásico: $\mathrm{eHf}_{1322 \mathrm{Ma}}=+16,5$ y eHf $_{1045,6 \mathrm{Ma}}=+1,6$; Esténico: $\mathrm{eHf}_{615,3 \mathrm{Ma}}=+13,6$ ); y nuevamente por magmas inicialmente de afinidad juvenil, aunque afectados por contaminación cortical (o simplemente con afinidad de arcos magmáticos antiguos re-trabajados) con edades tanto del Paleo-Proterozoico (Orosírico: eHf $_{1867,3}=-5.2$ ), como del Meso- (Esténico: $\left.\mathrm{eHf}_{1141,1 \mathrm{Ma}}=-5,9\right)$ y Neo-Proterozoico (Criogénico-Ediacárico : $\mathrm{eHf}_{812,1 \mathrm{Ma}}=-5,4 ; \mathrm{eHf}_{560 \mathrm{Ma}}=-4,0$ ).

Finalmente, los valores (eHf) de los zircones ígneos detríticos presentes en las meta-areniscas aflorantes en la franja Pescadero-Aratoca (unidad Filitas de San Pedro, según Mantilla, et al., 2015), apuntan a que estos minerales detríticos proceden igualmente del desmantelamiento de arcos magmáticos, en su momento formados posiblemente por magmas de afinidad juvenil $\left(\mathrm{eHf}_{1288 \mathrm{Ma}}=+0,3\right.$; $\mathrm{eHf}_{1012}$ $\left.\mathrm{Ma}=+0,5 ; \mathrm{eHf}_{993 \mathrm{Ma}}=+0,2 ; \mathrm{eHf}_{967 \mathrm{Ma}}=+0,2\right)$, los cuales temporalmente también se relacionan con eventos del MesoProterozoico, concretamente Ectásico $\left(\mathrm{eHf}_{1288 \mathrm{Ma}}=+0,3\right)$, Esténico $\left(\mathrm{eHf}_{1012 \mathrm{Ma}}=+0,5\right)$ y Tónico $\left(\mathrm{eHf}_{993 \mathrm{Ma}}=+0,2 ; \mathrm{eHf}_{967}\right.$ $\mathrm{Ma}=+0,2$; Neo-Proterozoico Temprano). Adicional a la presencia de estos zircones referidos, también se reconoce la presencia de zircones posiblemente derivados inicialmente de magmas de afinidad juvenil, aunque afectados por contaminación cortical (o simplemente con una afinidad de arcos magmáticos antiguos re-trabajados; $\mathrm{eHf}_{999 \mathrm{Ma}}=-0,6$; $\left.\mathrm{eHf}_{967 \mathrm{Ma}}=-0,7 ; \mathrm{eHf}_{482 \mathrm{Ma}}=-1,3 ; \mathrm{eHf}_{460 \mathrm{Ma}}=-3,1\right)$, temporalmente relacionados con el límite Esténico-Tónico (Meso-/NeoProterozoico), pero a diferencia de las unidades anteriores, también contiene zircones ígneos de de edad Ordovícico (Temprano y Medio).

Las anteriores interpretaciones se consideran de carácter preliminar, teniendo en cuenta que se requiere un numero mayor de análisis para fines de poder establecer si existen familias de circones detríticos de una misma edad, pero con diferentes valores épsilon $\mathrm{Hf}(\varepsilon \mathrm{Hf}>0$ ó $\varepsilon \mathrm{Hf}<0)$. 
Apoyados en los datos anteriormente referidos, es posible subrayar que existen evidentes diferencias entre las tres unidades metamórficas propuestas en Mantilla, et al., (2016) a cambio de la originalmente propuesta Formación Silgará (referida inicialmente en Ward, et al., 1973). En este contexto, una vez más se corrobora que las tres unidades propuestas (Esquistos del Silgará s.s.; Esquistos del Chiocamocha y; Filitas de San Pedro) no pueden continuar haciendo parte de una misma formación o unidad, debido a sus diferencias litológicas, grado de metamorfismo, máxima edad de depositación y proveniencia de sus protolitos (incluido por supuesto también sus zircones detríticos).

\section{Propuesta de un nuevo marco estratigráfico para el basamento metamórfico del Macizo de Santander}

\section{Consideraciones preliminares}

La unidad metamórfica más antigua del Macizo de Santander, el Gneis de Bucaramanga (la cual esta por fuera del alcance del presente estudio), ha sido considerada por Cordani, et al., (2005) como un remanente del Cinturón Grenvilliano de Laurentia. Los zircones detríticos presentes en ésta unidad tienen edades que oscilan entre $» 1600$ y $\gg 1200 \mathrm{Ma}$. Esto ha permitido indicar que la máxima edad de depositación del protolito del Gneis de Bucaramanga es de $\sim 1200 \mathrm{Ma}$ (límite entre el Estásico-Esténico). Los zircones detríticos con edades entre $\sim 1300$ y $\sim 1600$ Ma (Calímico-Ectásico), son considerados por los autores como derivados de las provincias geocronológicas del Cratón Amazónico, denominadas Rio Negro Juruena, Rondonian y Sunsás. Los eventos metamórficos que han afectado esta unidad (al igual que al Complejo de Garzón, y a los Gneises de Dibulla y Jojoncito), tuvieron lugar principalmente a los 1190-1140 Ma, y 1000-950 Ma. Una edad de metamorfismo más reciente también reportada para el Gneis de Bucaramanga por estos autores, entorno a los $864 \pm 66 \mathrm{Ma}$ (»Criogénico), podría estar relacionada con un evento de metamorfismo prácticamente desconocido en el Macizo de Santander. De corroborarse éste evento de metamorfismo, éste debió haber afectado también al protolito de la unidad esquistos del Silgará s.s. (?), con anterioridad a la depositación del protolito de la unidad Esquistos del Chicamocha (ver Figura 4).

Un modelo contrario a la afinidad Grenvilliana propuesto por Cordani, et al. (2005) para el rango 1.3-0.95 Ga, se documenta en Ibáñez, et al., (2011). Según estos últimos autores, la proveniencia de los zircones detríticos ígneos presentes en los Macizos de Garzón y Las Minas, al igual que las edades de metamorfismo (»1.15-0.98 Ga), se relacionan con la evolución del Orógeno del Putumayo (Orogenia Putumayense), el cual se interpreta como el resultado de la interacción colisional entre la Amazonía y la provincia Sveconorwegian del Báltico (contrario a la interacción colisional Amazonía-Laurentia propuesta en Cordani, et al., 2005). Aunque el estudio de Ibáñez, et al., (2011) no analizó muestras del Macizo de Santander, se infiere que éste (particularmente la unidad Gneis de Bucaramanga) también sería otra exposición aislada en los Andes del Norte de esa corteza propuesta (de edad Esténico-Tónico; »1200$1000 \mathrm{Ma}$ ), debido a su gran similitud con el Complejo de Garzón (Macizo de Garzón), es decir, también debió hacer parte de los terrenos Colombo-Oaxaqueños en los cuales se desarrolló la franja de arco magmático (fringing arc) Pericratónica que tuvo lugar principalmente a los $\sim 1.15 \mathrm{Ga}$ (Ibáñez, et al., 2011).

Extrapolando los datos reportados Ibáñez, et al., (2011) para el Macizo de Garzón (y de algunos afloramientos similares del basamento de las cuentas foreland de los Andes del Norte), la máxima edad de depositación del protolito del Gneis de Bucaramanga sería algo similar, es decir, entre $1016 \pm 5$ Ma y la edad del metamorfismo a los $992 \pm 8$ Ma (Esténico-Tónico).

La corteza en la cual se desarrollaron los eventos EsténicoTónicos antes referidos, se considera hace parte de la Provincia Rio Negro-Juruena, descrita en Tassinari y Macambira (1999). La presencia de gneises sienograníticos en el basamento del área de Araracuara (Amazonía Colombiana) con edades de $1756 \pm 18$ Ma y $1732 \pm 24$ $\mathrm{Ma}$; granitoides en los ríos Apaporis y Vaupés (con edades entre 1530 y $1588 \mathrm{Ma}$ (Calímico), y la presencia ocasional de zircones heredados en algunos de estos cuerpos ígneos Meso-Proterozoicos con edades que oscilan en el rango de $\sim 1600$ a $\sim 2000 \mathrm{Ma}$ (y granos puntuales de zircones tan antiguos como $2.5 \mathrm{Ga}$; según Ibáñez, et al., 2011), apuntan en ese mismo sentido. Un aspecto muy importante en éstas zonas referidas del escudo (tal como se resalta en el estudio citado), es la ausencia de evidencias de eventos magmáticos o metamórficos más jóvenes que $\sim 1.5$ Ga (evidencias de no perturbación de la provincia Rio Negro-Juruena, la cual hace parte del cratón Amazónico (de edad 1.8-1.55 Ga).

\section{Provenciencia de los zircones detríticos y propuesta de un nuevo marco estratigráfico para el basamento metamórfico del MS}

Apoyados en los aspectos geológicos referidos en el apartado anterior, es posible por consiguiente sugerir que los zircones detríticos presentes en la Unidad Esquistos del Silgará (s.s.); relacionados con magmas de afinidad juvenil del Estatérico $\left(\mathrm{eHf}_{1672 \mathrm{Ma}}=+9.3\right)$, Calímico $\left(\mathrm{eHf}_{1414 \mathrm{Ma}}=+10.3\right)$ y tal vez también aquellos del Ectásico $\left(\mathrm{eHf}_{1289 \mathrm{Ma}}=+0.8\right)$; se relacionan muy posiblemente con el desmantelamiento de rocas ígneas como las descritas en la Serranía de la Macarena (Ibáñez, et al., 2011) o por procesos de re-depositación (por ejemplo: erosión del Gneis de Bucaramanga? y redepositación de sus materiales que ahora constituirían el protolito de la Unidad Esquistos del Silgará s.s.). Los eventos magmáticos de afinidad juvenil que dieron origen a éstos zircones referidos, debieron estar estrechamente relacionados en el momento de su cristalización con eventos ígneos propios de la evolución de las provincias Rio Negro- 


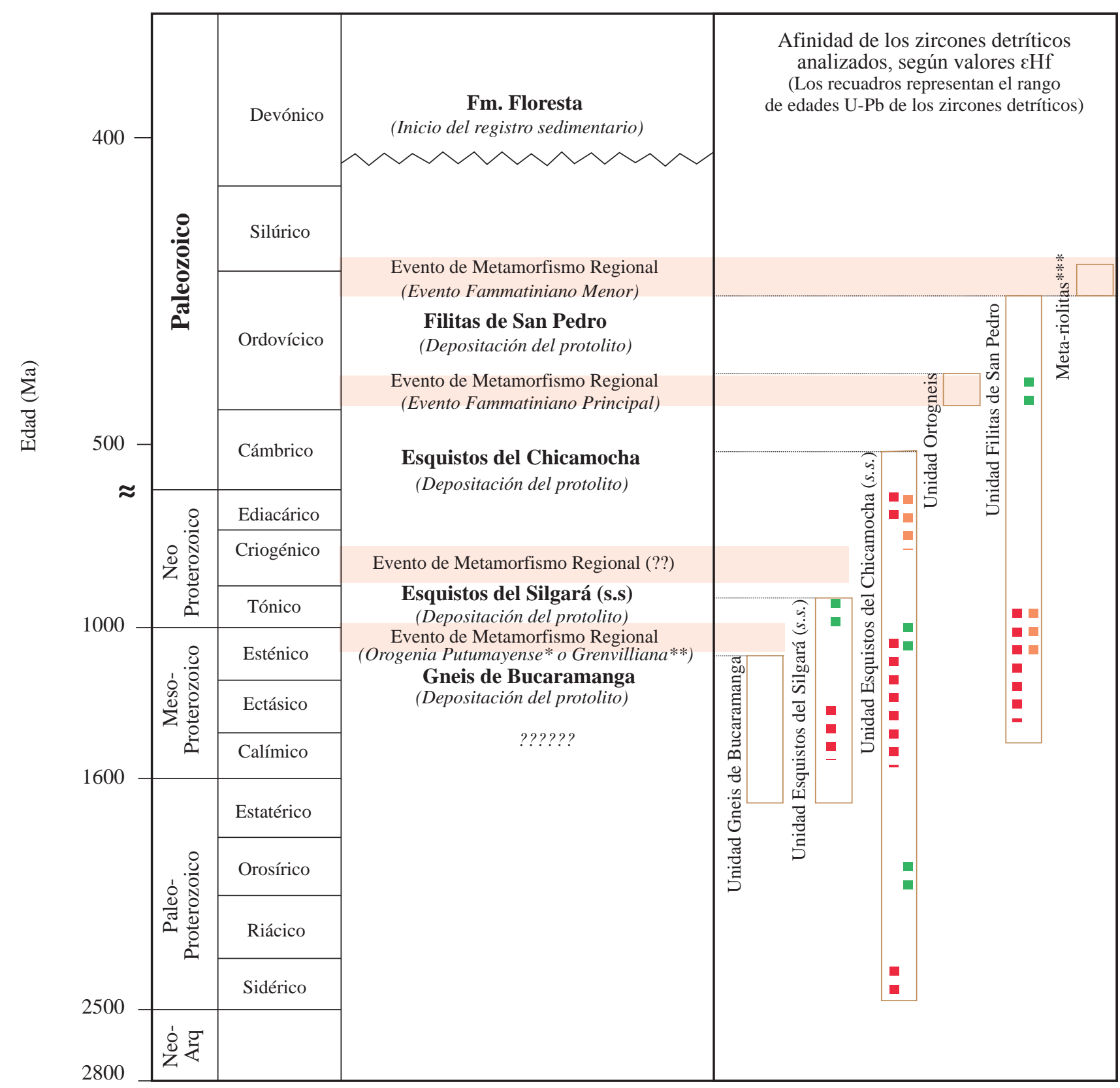

Figura 4. Columna estratigráfica generalizada para el basamento metamórfico del Macizo de Santander (la escala vertical del tiempo es arbitraria). La Formación Floresta correspondería a la primera unidad sedimentaria que cubre el basamento metamórfico del MS. El signo + representa el magmatismo sin-tectónico que tuvo lugar durante el desarrollo del Evento Orogénico Fammatiniano Principal (dando origen a la denominada unidad Ortogneis; de edad Ordovícico Temprano). * Según Modelo de Ibáñez et al., (2011); ** Según Modelo de Cordani et al., (2005); ***Según Mantilla, et al. 2015. A la derecha de la columna se señala la afinidad de los magmas (con base en los datos isotópicos de Hf) a partir de los cuales cristalizaron los zircones analizados (rojo: juveniles; naranja: corticales). El rango de edad de los zircones detríticos ígneos de la unidad Gneis de Bucaramanga, se apoya en datos de Cordani et al., (2005). Esquema elaborado con base en estudios previos (Ward et al., 1973; Clavijo et al., 1994; van der Lilej et al., 2015; Spikings et al, 2015; Mantilla et al., 2015 y 2016 , entre otros). Las unidades Esquistos del Silgará (s.s), Chicamocha y Filitas de San Pedro, conformaban la denominada Formación Silgará (en términos de Ward et al., 1973) ó unidad Esquistos del Silgará (en términos de Clavijo, 1994).

Juruena y Rondonian (descritas en Tassinari y Macambira, 1999). Sin embargo, los zircones detríticos con una afinidad propia de una componente cortical importante, de edad Tónico $\left(\mathrm{eHf}_{1000 \mathrm{Ma}}=-1.2, \mathrm{eHf}_{975 \mathrm{Ma}}=-3.2, \mathrm{eHf}_{965 \mathrm{Ma}}=-2.0\right.$,), se interpretan como derivados del magmatismo que tuvo lugar en las etapas finales de la Orogenia Putumayo (propuesta por Ibáñez, et al., 2011), aunque no se descarta la presencia de otra fuente ligeramente más joven $\left(\mathrm{eHf}_{881 \mathrm{Ma}}=-3.8\right.$ ?). 
Respecto a los zircones detríticos presentes en la unidad Esquistos del Chicamocha (franja Pescadero-Aratoca), es posible sugerir que aquellos zircones relacionados con magmas de afinidad juvenil del Paleo-Proterozoico (Sidérico; $\left.\mathrm{eHf}_{2402,2 \mathrm{Ma}}=+15\right)$ y magmas con afinidad cortical también del Paleo-Proterozoico (Orosírico: $\mathrm{eHf}_{1867,3 \mathrm{Ma}}=-5,2$ ), proceden del desmantelamiento de las rocas más antiguas del NW del Cratón Amazónico, al parecer localizadas en territorio de Venezuela y Surinam, en donde también se han reportado eventos magmáticos y metamórficos de edad Orosírico (De Roever, et al., (2010), e incluso eventos magmáticos y metamórficos aún mas antiguos (USGS y CVG, 1993; De Avelar, et al. 2003; Delor, et al. 2003; Tassinari, et al., 2004; Hildebrand, 2005; Da Rosa-Costa, et al. 2006). Respecto a las zircones formados principalmente por magmas de afinidad juvenil (Depleted Mantle-Related) de edad Calímico $\left(\mathrm{eHf}_{1534,5 \mathrm{Ma}}=+7,4\right)$ y Ectásico $\left(\mathrm{eHf}_{1322 \mathrm{Ma}}=+16,5\right)$, es posible nuevamente sugerir que estos están relacionados en el momento de su cristalización, también con eventos ígneos propios de las provincias Rio Negro-Juruena y Rondonian (descritas en Tassinari y Macambira, 1999). Sin embargo, los zircones detríticos con una componente magmática, de afinidad tanto juvenil como cortical, del Esténico $\left(\mathrm{eHf}_{1045,6}\right.$ $\mathrm{Ma}=+1,6$ e $\left._{1141,1 \mathrm{Ma}}=-5,9\right)$, al igual que en el caso anterior, se interpretan como derivados del magmatismo que tuvo lugar en las etapas finales de la Orogenia Putumayense (propuesta por Ibáñez, et al., 2011). Finalmente, los zircones detríticos del Ediacárico (finales del Neo-Proterozoico), con afinidades de magmas tanto juveniles $\left(\mathrm{eHf}_{615,3 \mathrm{Ma}}=\right.$ $+13,6)$ como corticales $\left(\mathrm{eHf}_{560 \mathrm{Ma}}=-4,0\right)$, resultan ser muy coincidentes temporalmente con la orogenia Brasilinao/ Pan-Africana (Neo-Proterozoico). Por esta razón, éstos zircones estarían relacionados con el desmantelamiento de un antiguo cinturón magmático de esta edad, actualmente enterrado debajo de la cuenca del Amazonas y cubierto durante el Eoceno-Oligoceno (según Chew, et al., 2007 y 2008). La presencia puntual de zircones detríticos en la unidad Esquistos del Chicamocha con magmas de afinidad cortical del Criogénico $\left(\mathrm{eHf}_{812,1 \mathrm{Ma}}=-5,4\right)$, no esta muy clara, aunque se sospecha que podría estar relacionado con algún evento ígneo que tuvo lugar con posterioridad a la Orogenia Grenvilliana (en términos de Cordani, et al., 2005) ó Orogenia Putumayense (en el sentido de Ibáñez, et al., 2011) e inicios de la depositación del protolito de la Unidad Esquistos del Chicamocha (Cámbrico Temprano a Medio, según Mantilla, et al., 2015).

Con relación a los zircones ígneos detríticos presentes en la unidad Filitas de San Pedro, con afinidad propia de magmas juveniles $\left(\mathrm{eHf}_{1288 \mathrm{Ma}}=+0,3\right.$; $\mathrm{eHf}_{1012 \mathrm{Ma}}=+0,5 ; \mathrm{eHf}_{993 \mathrm{Ma}}=+0,2$; $\left.\mathrm{eHf}_{967 \mathrm{Ma}}=+0,2\right)$ del Ectásico $\left(\mathrm{eHf}_{1288 \mathrm{Ma}}=+0,3\right)$, Esténico $\left(\mathrm{eHf}_{1012 \mathrm{Ma}}=+0,5\right.$; Meso-Proterozoico) y Tónico $\left(\mathrm{eHf}_{993}\right.$ $\mathrm{Ma}=+0,2 ; \mathrm{eHf}_{967 \mathrm{Ma}}=+0,2 ;$ Neo-Proterozoico Temprano); y de afinidades corticales también del Tacónico $\left(\mathrm{eHf}_{999 \mathrm{Ma}}=-0,6\right.$; $\left.\mathrm{eHf}_{967 \mathrm{Ma}}=-0,7\right)$; nuevamente se sugiere que estos podrían estar relacionados con los eventos magmáticos sintectónicos (simultaneos con el desarrollo del metamorfismo regional) que tuvieron lugar durante la evolución de la Orogenia Putumayense (propuesta por Ibáñez, et al., 2011; Weber, et al., 2010; Van der Lilej, 2015). A diferencia de las unidades anteriores, se resalta también la presencia de zircones ígneos de afinidad cortical de edad Ordovícico (Temprano y Medio; con valores $\mathrm{eHf}_{482 \mathrm{Ma}}=-1,3$; $\left.\mathrm{eHf}_{460 \mathrm{Ma}}=-3,1\right)$, los cuales al parecer están relacionados con el desmantelamiento de los granitos sin-tectónicos representados en la unidad Ortogneis (aflorantes en el Macizo de Santander). Esto, se basa en el hecho que estas rocas presentan características tanto de magmas con afinidad juvenil, como de magmas posiblemente contaminados con materiales corticales (ver Mantilla, et al., 2012 y Van der Lilej, 2013). En este sentido, es posible señalar que la depositación del protolito de esta unidad, incorporó fuentes relativamente más cercanas (relativamente mas autóctonas, es decir, fuentes intraFammatinianas formadas durante el evento orogénico principal), en comparación con los protolitos de las anteriores dos unidades.

Apoyados en los datos anteriormente referidos, los autores señalan la necesidad de profundizar en la tarea de diferenciar la unidad esquistosa de la franja P-A (tentativamente denominada en estudios previos como unidad Esquistos del Chicamocha), de la unidad Esquistos del Silgará (s.s.) aflorante en la franja M-C. Teniendo en cuenta estas consideraciones y los recientes datos publicados en la bibliografía (van der Lilej, et al, 2015; Mantilla, et al., 2015 y 2016, entre otros), se siguiere un nuevo marco estratigráfico para el basamento metamórfico del Macizo de Santander, el cual se resume a manera de columna estratigráfica, como aquella referida en la Figura 4. En ésta última, adicionalmente también se señalan los posibles eventos de metamorfismo regional que se registran en el Macizo de Santander.

\section{Conclusiones}

El estudio de los zircones detríticos presentes en las rocas esquistosas aflorantes tanto en las franjas MatanzaCachirí (M-C), como Piedecuesta-Aratoca (P-A), muestra poblaciones de zircones comunes, los cuales guardan relación con magmas de afinidad juvenil (eHf $>0)$ de edades tanto del Paleo-Proterozoico Tardío (Estatérico), como del Meso-/Neo-Proterozoico (con poblaciones en el rango de edad Calímico-Ectásico y Esténico-Tónico). La presencia en ambas unidades de zircones ígneos con afinidad cortical también del rango Esténico-Tónico (comparativamente los más abundantes), permite sugerir una fuente de sedimentos relacionada con una corteza continental ligada a la evolución de la Orogenia Putumayense (según Modelo de Ibáñez, et al., 2011) o Grenvilliana (según Modelo de Cordani, et al., 2005 y Chew, et al., 2008). A pesar de éstos rasgos comunes, también es muy evidente la diferencia entre estas dos franjas metamórficas, especialmente debido a: (1) la presencia de poblaciones de zircones más antiguos (por ejemplo, zircones con afinidad mantélica de edad Sidérico; y con 
afinidad cortical de edad Orosírico; también hay presencia puntual de zircones Arqueanos) y; (2) presencia de zircones más jóvenes (de afinidad cortical del Criogénico; y de afinidad mantélica de edad Ediacárico). Los zircones ígneos más antiguos, se relacionan con fuentes de sedimentos localizadas en las provincias Rio Negro-Juruena y Rondonia (o incluso Venturi-Tapajos). La fuente de sedimentos más jóvenes de edad Ediacárico (zircones de afinidad tanto mantélica, como cortical; y temporalmente coincidentes con la orogenia Brasiliano/Pan-Africana), se interpretan como procedentes del desmantelamiento de un antiguo cinturón magmático desarrollado durante el rompimiento del supercontinente Rodinia (actualmente enterrado debajo de la cuenca del Amazonas, el cual se encontraría cubierto por sedimentos del Eoceno-Oligoceno, según Chew, et al., 2007 y 2008).

Los contrastes referidos entre las dos franjas metamórficas antes mencionadas, apoyan la necesidad de diferenciar la unidad esquistosa de la franja P-A (tentativamente denominada en estudios previos como unidad Esquistos del Chicamocha), de la unidad Esquistos del Silgará (s.s.) aflorante en la franja M-C.

Finalmente, los zircones ígneos detríticos de la unidad Filitas de San Pedro, se caracterizan por presentar zircones ígneos del Ordovícico Temprano y Medio (además de las ya referidas poblaciones del Meso- y Neo-Proterozoico). La presencia de ésta población más joven de zircones con valores $\mathrm{eHf}<0$, se relaciona con el desmantelamiento de los granitos sin-tectónicos representados en la unidad Ortogneis (aflorantes en el Macizo de Santander).

En el contexto de los nuevos datos reportados, se propone un nuevo marco estratigráfico para el basamento metamórfico del Macizo de Santander, representado a manera de columana estratigráfica en la Figura 4.

\section{Agradecimientos}

Los autores expresan su agradecimiento a la Universidad Industrial de Santander (UIS), el apoyo financiero brindado a este trabajo mediante el proyecto 1799 "Condiciones y edad de metamorfismo de las metasedimentitas aflorantes en el área del municipio de Mogotes (Macizo de Santander, Colombia).” A la Escuela de Geología y al grupo GIGBA (Grupo de investigación en Geología Básica y Aplicada), por apoyar siempre las actividades encaminadas a generar nuevo conocimiento geológico de nuestro territorio nacional. A las autoridades civiles, militares y eclesiásticas de las áreas del Departamento de Santander visitadas durante el desarrollo del presente estudio, por la amabilidad y colaboración. Al Geólogo Camilo Arenas por su colaboración en la elaboración de la figura 1.

Un agradecimiento especial a los colegas Hernando Mendoza, Jairo Clavijo y Giovanny Jiménez, por sus valiosos comentarios y discusiones.
Los autores expresan su profunda gratitud a los evaluadores anónimos del presente trabajo, cuyos valliosos comentarios ayudaron a mejorar este manuscrito.

\section{Conflicto de interés}

Los autores declaran no tener conflicto de interés

\section{Bibliografía}

Albarède, F., Scherer, E.E., Blichert-Toft, J., Rosing, M.T., Simionovici, A., Bizzarro, M., 2006. Gamma-ray irradiation in the early solar system and the conundrum of the ${ }^{176} \mathrm{Lu}$ decay constant. Geochimica and Cosmochimica Acta, 70: 1261-1270.

Amelin, Y., Lee, D.Ch., Halliday, A. N., Pidgeon, R. T. (1999). Nature of the Earth's earliest crust from hafnium isotopes in single detrital zircons. Nature, 399 (20): 252-255.

Andres, M., Blichert-Toftb, J., Schilling, J. (2004). Nature of the depleted upper mantle beneath the Atlantic: evidence from $\mathrm{Hf}$ isotopes in normal mid-ocean ridge basalts from $79^{\circ} \mathrm{N}$ to $55^{\circ} \mathrm{S}$. Earth and Planetary Science Letters, 225: 89-103

Arvizu, H. E., Iriondo, A. (2011). Estudios isotópicos de Hf en zircones de granitoides pérmicos en el NW de México: Evidencia de mezcla de magmas generados a partir de la fusión de múltiples fuentes corticales. Revista Mexicana de Ciencias Geológicas, 28 (3): 493-518.

Bhatia, M.R., Crook, K.A.W. (1986). Trace element characteristics of graywackes and tectonic setting discrimination of sedimentary basins. Contributions to Mineralogy and Petrology, 92: 181-193.

Blichert-Toft, J., Albarède, F. (1997). The LueHf isotope geochemistry of chondrites and the evolution of the mantlecrust system. Earth and Planetary Science Letters, 148: 243-258.

Blichert-Toft, J., Chauvel, C., Albarède, F. (1997). Separation of $\mathrm{Hf}$ and $\mathrm{Lu}$ for high- precision isotope analysis of rock samples by magnetic sector-multiple collector ICP-MS. Contributions to Mineralogy and Petrology, 127: 248-260.

Bouvier, A., Vervoort, J.D., and Patchett, P.J. (2008). The LuHf and Sm-Nd isotopic composition of CHUR: Constraints from unequilibriated chondrites and implications for the bulk composition of terrestrial planets: Earth and Planetary Science Letters, 273: 48-57.

Boinet, T., Bourgois, J., Bellon, H. y Toussaint, J. (1985). Age et repartition du magmatism Premesozoique des Andes de Colombie. Comptes rendus hebdomadaires des séaces de L'Académie des Sciences. Serie D: SciencesNaturalles, 300 (II): 445-450.

Botello, F., Mantilla, F. L.C., Colegial, G. J. (2014). Edad U-Pb en zircones y contexto tectónico de formación del Granito de Durania (Macizo de Santander, Colombia). Memorias XI Semana Técnica de Geología y I Geosciences anual meeting. UIS. Bucaramanga, 11 al 15 de Agosto de 2014.

Chang, Z., Vervoort, J.D., Knaack, C., and McClelland, W.C. (2006). U-Pb dating of zircon by LA-ICP-MS. Geochemistry, Geophysics, Geosystems, 7 (5): 1-14. 
Chew, D.M., Schaltegger, U., Košler, J., Whitehouse, M.J., Gutjahr, M., Spikings, R.A., Miškovíc, A. (2007). $\mathrm{U}-\mathrm{Pb}$ geochronologic evidence for the evolution of the Gondwanan margin of the north-central Andes. Geological Society of America Bulletin, 119: 697-711.

Chew, D.M., Magna, T., Kirkland, C.L., Miskovic, A., Cardona, A., Spikings, R., Schaltegger, U. (2008). Detrital zircon fingerprint of the Proto-Andes: evidence for a Neoproterozoic active margin? Precambrian Research, 167: 186-200.

Clavijo, J. (1994). Mapa geológico generalizado del Departamento de Norte de Santander, Memoria explicativa. Informe interno INGEOMINAS, $67 \mathrm{p}$.

Cordani, U., Cardona, A., Jimenez, D., Liu, D., Nutman, A. (2005). Geochronology of Proterozoic basement inliers in Colombian Andes: tectonic history of remnants of a fragmented grenville belt. in: terrane processes at margins of gondwana. Geological Society, London, Special Publications. Edited by Vaughan, A.; Leat, P.; Pankhurst, R., 246: 329-346.

Cordani, U.G., Sato, K., Teixeira, W., Tassinari, C.G., and Basei, M.A.S. (2000). In Cordani, U.G., Milani, E.J., Thomaz Filho, A., and Campos Neto, M.C., eds., Tectonic Evolution of South America: Rio de Janeiro, 31st International Geological Congress, Institut de Recherche pour le Développement, 19-40.

De Roever, E.W.F., Lafon, J-M., Delor, C., 3, Guerrot, C. (2010). Orosirian magmatism and metamorphism in Surinam: new geochronological constraints. $45^{\circ}$ Congresso Brasileiro de Geologia. Belém, 26 de Setembro a 01 de Outubro de 2010. Poster.

Da Rosa-Costa, L., Lafon, J-M., Delor, C. (2006). Zircon geochronology and Sm-Nd isotopic study: Further constraints for the Archean and Paleoproterozoic geodynamical evolution of the southeastern Guiana Shield, north of Amazonian Craton, Brazil. Gondwana Research, 10: $277-300$.

De Avelar, V. G., Lafon, J-M, Delor, C., Guerrot, C., Lahondére, D. (2003). Archean cristal remmants in the easternmost part of the Guiana Shield: $\mathrm{Pb}-\mathrm{Pb}$ and $\mathrm{Sm}-\mathrm{Nd}$ geochronological evidence for Mesoarchean versus Neoarchean signatures. Géologie de la France, (2-3-4), 83-99.

Delor, C., Roever, E. W. F., Lafon, J-M., Lahondére, D., Rossi, Ph., Cocherie, A., Guerrot, C., Potrel, A. (2003). The Bakhuis ultrahigh-temperature granulite belt (Suriname): II. implications for late Transamazonian crustal stretching in a revised Guiana Shield framework. Géologie de la France, (2-3-4), 207-230.

Fralick, P. W., Kronberg, B. (1997). Geochemical discrimination of clastic sedimentary rock sources. Sed. Geol., 113, 111-124.

García, C., Ríos, C. (1999). Metamorfismo y metalogénia asociada del Macizo de Santander, Cordillera Oriental, Colombia. Informe final Proyecto de Investigación 102-05083-95 Colciencias-Universidad Industrial de Santander (Bucaramanga), 191p.
García-Ramírez, C., Ríos, C. (2004). Occurrence and significance of the polymorphs of $\mathrm{Al}_{2} \mathrm{SiO}_{5}$ in metamorphic rocks of the Santander Massif, Eastern Cordillera (Colombian Andes). Boletin de Geología, 26 (43): 23-38

Goldsmith, R., Marvin, R.F., Mehnert, H.H. (1971). Radiometric ages in the Santander Massif, Eastern Cordillera, Colombian Andes. U.S. Geological Survey Professional. Paper 750-D, D44-D49.

Hildebrand, R. S. (2005). Autochthonous and allochthonous strata of the El Callao greenstone belt: Implications for the nature of the Paleoproterozoic Trans-Amazonian orogeny and the origin of gold-bearing shear zones in the El Callao mining district, Guayana shield, Venezuela. Precambrian Research 143: 75-86.

Ibanez-Mejia, M., Ruiz, J., Valencia, V.A., Cardona, A., Gehrels, G.E., and Mora, A.R. (2011). The Putumayo Orogen of Amazonia and its implications for Rodinia reconstructions: New $\mathrm{U}-\mathrm{Pb}$ geochronological insights into the Proterozoic tectonic evolution of northwestern South America: Precambrian Research, 191 (1): 58-77.

Hoang, L. V., F.-Y. Wu, P. D. Clift, A. Wysocka, and A. Swierczewska (2009). Evaluating the evolution of the Red River system based on in situ U-Pb dating and Hf isotope analysis of zircons. Geochemistry, Geophysics, Geosystems, 10 (11). doi:10.1029/2009GC002819.

Kemp, A.I.S., Wormald, R.J., Whitehouse, M.J., Price, R.C. (2005). Hf isotopes in zircon reveal contrasting sources and crystallization histories for alkaline to peralkaline granites of Temora, southeastern Australia. Geology, 33 (10): $797-$ 800 .

Koglin, N., Zeh, A., Frimmel, H. E., Gerdes, A. (2010). New constraints on the auriferous Witwatersrand sediment provenance from combined detrital zircon $\mathrm{U}-\mathrm{Pb}$ and $\mathrm{Lu}-$ Hf isotope data for the Eldorado Reef (Central Rand Group, South Africa). Precambrian Research, 183: 817-824.

Machado, N., Simonetti, A. (2001). U-Pb dating and Hf isotopic composition of zircon by Laser Ablation-MC-ICP-MS. In: Laser Ablation-ICPMS in the Earth Sciences: Principles and Applications, pp. 121-146 (Chapter 9).

Mantilla, Figueroa. L. C., Bissig, T., Valencia, V., Craig, H. (2013). The magmatic history of the Vetas-California mining district; Santander Massif, Eastern Cordillera, Colombia. Journal of South American Earth Sciences, 45: 235-249.

Mantilla, Figueroa. L. C., Bissig, T., Cottle, J. M., Hart, C. 2012. Remains of early Ordovician mantle-derived magmatism in the Santander Massif (Colombian Eastern Cordillera). Journal of South American Earth Sciences 38: 1-12.

Mantilla-Figueroa, L., García-Ramírez, C., Ríos-Reyes, C., Castellanos, O., Valencia, V., Camacho, D. (2015). Geocronología U-Pb en circones detríticos de rocas metasedimentarias del Macizo de Santander (Cordillera Oriental, Colombia): Implicaciones estratigráficas. Memorias XV Congreso Colombiano de Geología, Bucaramanga, Agosto 31 a Septiembre 5 de 2015, p.p. 444-450. 
Mantilla, Figueroa. L. C., García, C. A., Valencia, V. (2016). Propuesta de escisión de la denominada 'Formación Silgará' (Macizo de Santander, Colombia), a partir de edades U-Pb en zircones detríticos. Boletín de Geología, 38 (1): 33-47.

Moreno-Sánchez, M., Gómez-Cruz, A. d. J., y Castillo-González, H. (2005). La Formación Floresta Metamorfoseada (sensu Ward et al., 1973) no es la Formación Floresta sin metamorfosear. Memorias X Congreso Colombiano de Geología. Bogotá, pp. 1-7.

Nebel, O., Rapp, R. P., Yaxley, G. M. (2014). The role of detrital zircons in Hadean crustal research. Lithos, 190: 313-327.

Neves, S. P., Alcantara, V. C. (2010). Geochemistry of orthogneisses and metasedimentary rocks across a proposed terrane boundary in the Central Domain of Borborema Province, NE Brazil: Geodynamic implications. Journal of South American Earth Sciences, 29: 498-511

Ramos, V.A. (2010). The Grenville-age basement of the Andes: Journal of South American Earth Sciences, 29 (1): 77-91.

Restrepo-Moreno, S. (2009). Long-term morphotectonic evolution and denudation chronology of the Antioqueño plateau, Cordillera Central, Colombia. Ph.D thesis, University of Florida, 233p

Restrepo-Pace, P.A., Cediel, F. (2010). Northern South America basement tectonics and implications for paleocontinental reconstructions of the Americas. Journal of South American Earth Sciences, 29: 764-771.

Ríos, C., García-Ramírez, C., Takasu, A. (2003). Tectonometamorphic evolution of the Silgara Formation metamorphic rocks in the southwestern Santander Massif, Colombian Andes. Journal of South American Earth Sciences, 16: 133-154

Roser, B.P., Korsch, R.J. (1986). Determination of tectonic setting of sandstone- mudstone suites using $\mathrm{SiO} 2$ content and $\mathrm{K} 2 \mathrm{O} / \mathrm{Na} 2 \mathrm{O}$ ratio. J. Geol., 94.

Royero, J., Vargas, G. (1999). Geología del Departamento de Santander. Ingeominas.

Royero, G.J.M., Clavijo, J. (2001). Mapa Geológico generalizado departamento de Santander. Escala 1: 400.000. Informe Ingeominas, $92 \mathrm{p}$.

Scherer, E., Münker, C., Mezger, K. (2001). Calibration of the lutetium-hafnium clock. Science 293: 683-687.

Siebel, W., Van den haute, P. (2007). Radiometric dating and tracing. In: Radiochemistry and Nuclear Chemistry, [Ed. Sandor Nagy]. Encyclopedia of Life Support Systems (EOLSS), Developed under the Auspices of the UNESCO, Eolss Publishers, Oxford UK, [http://www.eolss.net]

Spikings, R. Cochrane, R., Villagomez, D., Van der Lelij, R., Vallejo, C., Winklerf, W. Beate, B. (2015). The geological history of northwestern South America: from Pangaea to the early collision of the Caribbean Large Igneous Province (290-75 Ma). Gondwana Research, 27 (1): 95-139.
Tassinari, C. C.G., Munhá, J. M. U., Teixera, W., Palacios, T., Nutman, A. P., Sosa S. C., Santos, A. P., Calado, B. O. (2004). The Imataca Complex, NW Amazonian Craton, Venezuela: Crustal evolution and integration of geochronological and petrological cooling histories. Episodes, 27 (1): 3-12.

Tassinari, C., and Macambira, M. (1999). Geological provinces of the Amazonían Craton. Episodes, 22: 173-182.

Taylor, S. R., McLennan, S. M. (1985). The Continental Crust, its Composition and Evolution (Blackwell Scientific, Oxford).

Turkina, O. M., Lepekhina, E. N., Berezhnaya, N. G., Kapitonov, I. N. (2014). U-Pb age and Lu-Hf Isotope Systematics of Detrital Zircons from Paragneiss of the Bulun Block (Sharyzhalgai Uplift of the Siberian Craton Basement). Doklady Akademii Nauk, 458 (5): 582-589.

U.S Geological Survey and Corporación Venezolana de Guayana, Técnica Minera C. A. (1993). Geology and Mineral Resource Assessment of the Venezuelan Guayana Shield. U.S. Geological Survey Bulletin 2062. 128 p.

Van Der Lelij, R. (2013). Reconstructing north-western Gondwana with implications for the evolution of the Iapetus and Rheic Oceans: a geochronological, thermochronological and geochemical study. Thèse de doctorat, Univ. Genève, no. 4581, 248p. http://archive-ouverte.unige.ch/unige:31653.

Van Der Lelij, R., Spikings, R., Ulianov, A., Chiaradia, M., Mora, A. (2015). Palaeozoic to Early Jurassic history of the northwestern corner of Gondwana, and implications for the evolution of the Iapetus, Rh..., Gondwana Research.doi. org/10.1016/j.gr.2015.01.011

Veevers J. J., Belousova E. A., Saeed A., Sircombe K., Cooper A. F. and Read S. E. (2006). Pan-Gondwana detrital zircons from Australia analysed for Hf-isotopes and trace elements reflect an ice-covered Antarctic provenance of 700-500 Ma age, TDM of 2.0-1.0 Ga, and alkaline affinity. Earth Sci. Rev., 76: 135-174.

Villamizar, D., Rueda, L. (2014). Petrografía de los Esquistos del Silgará en la franja Matanza.Cachirí-Turbay. Trabajo de grado. Escuela de Geología, Universidad Industrial de Santander, 129p.

Vervoort, J.D., Patchett, P.J., Soderlund, U., Baker, M. (2004). The isotopic composition of $\mathrm{Yb}$ and the precise and accurate determination of $\mathrm{Lu}$ concentrations and $\mathrm{Lu} / \mathrm{Hf}$ ratios by isotope dilution using MC-ICP-MS. Geochem. Geophys. Geosyst. 5. doi:10.1029/2004GC000721.

Vervoort, J. and Kemp, A. (2016). Clarifying the zircon Hf isotope record of crust-mantle evolution. Chemical Geology, 425: $65-75$

Ward, D., Goldsmith, R., Cruz, B., Jaramillo, C., Restrepo, H. (1973). Geología de los Cuadrángulos H-12, Bucaramanga y H-13, Pamplona, Departamento de Santander. U.S. Geological Survey e Ingeominas. Boletín Geológico, XXI (1-3): 1-132.

Weaver, B., Tarney, J. (1984). Empirical approach to estimating the composition of the continental crust. Nature, 310: 575-577 
Weber, B., Scherer, E.E., Schulze, C., Valencia, V.A. Montecinos, P., Mezger, K., and Ruiz, J. (2010). U-Pb and $\mathrm{Lu}-\mathrm{Hf}$ isotope systematics of lower crust from centralsouthern Mexico- Geodynamic significance of Oaxaquia in a Rodinia Realm: Precambrian Research, 182 (1): 149-162.

Yang, Z. N., Yang, K. G., Xu, Y., Deng, X., Cheng, W., Long, Z. Y. (2015). Zircon U-Pb geochronology, Hf isotopic composition, and geological implications of the Neoproterozoic meta-sedimentary rocks in SuizhouZaoyang area, the northern Yangtze Block. Science China: Earth Sciences, doi: 10.1007/s11430-015-5073.
Zeh, A., Gerdes, A., Barton, J. (2009). Archean Accretion and Crustal Evolution of the Kalahari Cratonçthe Zircon Age and Hf Isotope Record of Granitic Rocks from Barberton/ Swaziland to the Francistown Arc. Journal of Petrology, 50:933-966, doi:10.1093/petrology/egp027

Zeh, A., Gerdes, A., Heubeck, C. (2013). U-Pb and Hf isotope data of detrital zircons from the Barberton Greenstone Belt: constraints on provenance and Archaean crustal evolution. Journal of the Geological Society, 170: 215-223. doi:10.1144/jgs2011-162 